\title{
Psychosocial interventions for smoking cessation in patients with coronary heart disease (Review)
}

\author{
Barth J, Critchley J, Bengel J
}

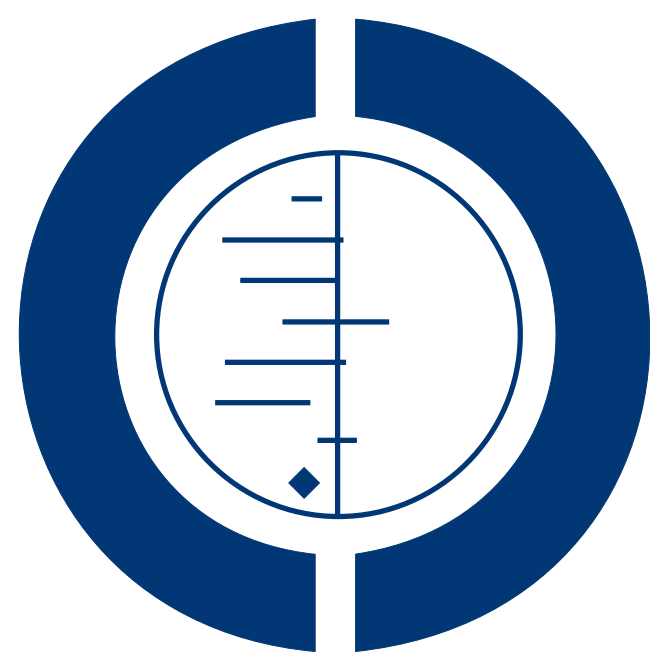

THE COCHRANE COLLABORATION ${ }^{\circledR}$

This is a reprint of a Cochrane review, prepared and maintained by The Cochrane Collaboration and published in The Cochrane Library 2008, Issue 1

http://www.thecochranelibrary.com

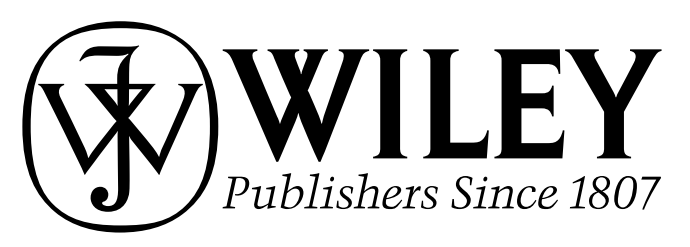

Psychosocial interventions for smoking cessation in patients with coronary heart disease (Review)

Copyright $\odot 2008$ The Cochrane Collaboration. Published by John Wiley \& Sons, Ltd 
TABLE OF CONTENTS

ABSTRACT . . . . . . . . . . . . . . . . . . . . . . . . . . . . . . . . . . .

PLAIN LANGUAGE SUMMARY . . . . . . . . . . . . . . . . . . . . . . . . . . . . . . . . . . . .

BACKGROUND . . . . . . . . . . . . . . . . . . . . . . . . . . . . . . . . . . . . . 2

OBJECTIVES . . . . . . . . . . . . . . . . . . . . . . . . . . . . . . . . . . . . . . . . . . . . 2

CRITERIA FOR CONSIDERING STUDIES FOR THIS REVIEW . . . . . . . . . . . . . . . . . . . . . . . . . . .

SEARCH METHODS FOR IDENTIFICATION OF STUDIES . . . . . . . . . . . . . . . . . . . . . . . . . . . . 3

METHODS OF THE REVIEW . . . . . . . . . . . . . . . . . . . . . . . . . . . . . . . . . . . . . . . . . . . . . . c c 4

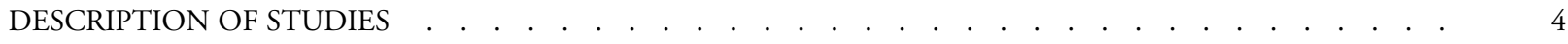

METHODOLOGICAL QUALITY . . . . . . . . . . . . . . . . . . . . . . . . . . . . . . . . . . . . . . . .

RESULTS . . . . . . . . . . . . . . . . . . . . . . . . . . . . . . . . . . . . . . . 5

DISCUSSION . . . . . . . . . . . . . . . . . . . . . . . . . . . . . . . . . . . . . 6

AUTHORS' CONCLUSIONS . . . . . . . . . . . . . . . . . . . . . . . . . . . . . . . . . . . . . . .

NOTES . . . . . . . . . . . . . . . . . . . . . . . . . . . . . . . . . . . . . . . . . . . . . . . . . . .

POTENTIAL CONFLICT OF INTEREST . . . . . . . . . . . . . . . . . . . . . . . . . . . . . . . . . . . . .

ACKNOWLEDGEMENTS . . . . . . . . . . . . . . . . . . . . . . . . . . . . . . . . . . . . . . . . . . .

SOURCES OF SUPPORT . . . . . . . . . . . . . . . . . . . . . . . . . . . . . . . . . . . . . . . . . . . . . .

REFERENCES . . . . . . . . . . . . . . . . . . . . . . . . . . . . . . . . . . . . . 7

TABLES . . . . . . . . . . . . . . . . . . . . . . . . . . . . . . . . . . . . . . . 13

Characteristics of included studies . . . . . . . . . . . . . . . . . . . . . . . . . . . . . . . . . . .

Characteristics of excluded studies . . . . . . . . . . . . . . . . . . . . . . . . . . . . . . . . . . . . $\quad$. 19

ADDITIONAL TABLES . . . . . . . . . . . . . . . . . . . . . . . . . . . . . . . . . . . . . . . . . . .

Table 01. EMBASE search strategy . . . . . . . . . . . . . . . . . . . . . . . . . . . . . . . . . . . . . . . 21

Table 02. Search strategy for MEDLINE, Pre-MEDLINE, BIOSIS and Journals@Ovid ～. . . . . . . . . . . . 22

Table 03. Search strategy for PsycINFO . . . . . . . . . . . . . . . . . . . . . . . . . . . . . . . . . . 22

Table 04. Search strategy for PSYNDEXplus . . . . . . . . . . . . . . . . . . . . . . . . . . 23

ANALYSES . . . . . . . . . . . . . . . . . . . . . . . . . . . . . . . . . . . . . . . . . . . . . . .

Comparison 01. Efficacy of psychosocial interventions on abstinence (6 to 12 months; all trials) . . . . . . . . . 24

Comparison 02. Sensitivity analysis validation (abstinence 6 to 12 months) . . . . . . . . . . . . . . . . . . . . 25

Comparison 03. Grouped by type of intervention (6 to 12 months) $\quad$. $\quad . \quad$. . . . . . . . . . . . . . . . . . . . . . $\quad 25$

Comparison 04 . Sensitivity analysis brief / intense intervention (6 to 12 months) . . . . . . . . . . . . . . . . $\quad 25$

Comparison 05. Efficacy of psychosocial interventions on long term abstinence (five years) . . . . . . . . . . . . $\quad 25$

COVER SHEET . . . . . . . . . . . . . . . . . . . . . . . . . . . . . . . . . . . . . . . . . . . . . 25

GRAPHS AND OTHER TABLES . . . . . . . . . . . . . . . . . . . . . . . . . . . . . . . . . . . . . . . . . .

Figure 01. Funnel plot . . . . . . . . . . . . . . . . . . . . . . . . . . . . . . . . . . . . . . . . $\quad . \quad 26$

Analysis 01.01. Comparison 01 Efficacy of psychosocial interventions on abstinence (6 to 12 months; all trials), Outcome 27 01 Abstinence 6 to 12 months (ITT preferred and OM)

Analysis 01.02. Comparison 01 Efficacy of psychosocial interventions on abstinence ( 6 to 12 months; all trials), Outcome 28 02 Abstinence 6 to 12 months (ITT preferred and OM)

Analysis 01.03. Comparison 01 Efficacy of psychosocial interventions on abstinence ( 6 to 12 months; all trials), Outcome 03 Abstinence 6 to 12 months (ITT only)

Analysis 02.01. Comparison 02 Sensitivity analysis validation (abstinence 6 to 12 months), Outcome 01 Abstinence at 6 to 12 months

Analysis 03.01. Comparison 03 Grouped by type of intervention (6 to 12 months), Outcome 01 Abstinence 6 to 12 months BEHAVIORAL THERAPY

Analysis 03.02. Comparison 03 Grouped by type of intervention (6 to 12 months), Outcome 02 Abstinence 6 to 12 months TELEPHONE SUPPORT

Analysis 03.03 . Comparison 03 Grouped by type of intervention ( 6 to 12 months), Outcome 03 Abstinence 6 to 12 months SELF HELP MATERIALS

Analysis 03.04. Comparison 03 Grouped by type of intervention (6 to 12 months), Outcome 04 Abstinence 6 to 12 months Specific vs. Multi-Risk-Factor Intervention

Psychosocial interventions for smoking cessation in patients with coronary heart disease (Review)

Copyright (๑) 2008 The Cochrane Collaboration. Published by John Wiley \& Sons, Ltd

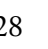


Analysis 04.01. Comparison 04 Sensitivity analysis brief / intense intervention (6 to 12 months), Outcome 01 Abstinence

6 to 12 months all studie

Analysis 05.01. Comparison 05 Efficacy of psychosocial interventions on long term abstinence (five years), Outcome 01 Abstinence five years (OM only)

Analysis 05.02. Comparison 05 Efficacy of psychosocial interventions on long term abstinence (five years), Outcome 02 Abstinence five years (ITT only) 


\title{
Psychosocial interventions for smoking cessation in patients with coronary heart disease (Review)
}

\author{
Barth J, Critchley J, Bengel J
}

Status: New

This record should be cited as:

Barth J, Critchley J, Bengel J. Psychosocial interventions for smoking cessation in patients with coronary heart disease. Cochrane Database of Systematic Reviews 2008, Issue 1. Art. No.: CD006886. DOI: 10.1002/14651858.CD006886.

This version first published online: 23 January 2008 in Issue 1, 2008.

Date of most recent substantive amendment: 03 October 2007

\begin{abstract}
A B S T R A C T
Background

Quitting smoking improves prognosis after a cardiac event, but many patients continue to smoke, and improved cessation aids are urgently required.
\end{abstract}

\section{Objectives}

To assess the effectiveness of psychosocial interventions such as behavioural therapeutic intervention, telephone support and self-help interventions in helping people with coronary heart disease (CHD) to quit smoking.

\section{Search strategy}

The Cochrane Central Register of Controlled Trials (issue 2 2003), MEDLINE, EMBASE, PsycINFO and PSYNDEX were searched from the start of the database to August 2003. Results were supplemented by cross-checking references, and handsearches in selected journals and systematic reviews.

\section{Selection criteria}

Randomised controlled studies (RCTs) in patients with CHD with a minimum follow-up of 6 months. After initial selection of the studies three trials with methodological flaws (e.g. high drop out) were excluded.

Data collection and analysis

Abstinence rates were computed according to an intention to treat analysis if possible, or if not on follow-up results only.

\section{Main results}

We found 16 RCTs meeting inclusion criteria. Interventions consist of behavioural therapeutic approaches, telephone support and selfhelp material and were either focused on smoking cessation alone or addressed several risk factors. The trials mostly included older male patients with CHD, predominantly myocardial infarction. Overall there was a positive effect of interventions on abstinence after 6 to 12 months (odds ratio (OR) 1.66, 95\% confidence interval (CI) 1.25 to 2.22), but substantial heterogeneity between trials. Studies with validated assessment of smoking status at follow-up had lower efficacy (OR 1.44, 95\% CI 0.99 to 2.11) than non-validated trials (OR 1.92, 95\% CI 1.26 to 2.93). Studies were clustered by intervention strategy and intensity of the intervention. Clustering reduced heterogeneity, although many trials used more than one type of intervention. The ORs for different strategies were similar (behavioural therapies OR 1.69, 95\% CI 1.33 to 2.14; telephone support OR 1.58, 95\% CI 1.28 to 1.97; self-help OR 1.48, 95\% CI 1.11 to 1.96). More intense interventions showed increased quit rates (OR 1.98, 95\% CI 1.49 to 2.65) whereas brief interventions did not appear effective (OR $0.92,95 \%$ CI 0.70 to 1.22). Two trials had longer term follow-up, and did not show any benefits after 5 years.

\section{Authors' conclusions}

Psychosocial smoking cessation interventions are effective in promoting abstinence at 1 year, provided they are of sufficient duration. Further studies, with longer follow-up, should compare different psychosocial intervention strategies, or the addition of a psychosocial intervention strategy to pharmacological therapy (e.g. nicotine replacement therapy) compared with pharmacological treatment alone. 


\section{PLAIN LANGUAGE SUMMARY}

Psychosocial smoking cessation interventions such as behavioural counselling, telephone support and self-help interventions are effective in helping people with coronary heart disease stop smoking. Smoking is a risk factor for coronary heart disease and stopping smoking lowers that risk. Psychosocial smoking cessation interventions such as behavioural therapy, telephone support and self-help materials are effective in helping coronary heart disease patients to stop smoking, if they are provided for over 1 month. We found evidence that psychosocial interventions increased quit rates after 6 months. Most trials used a mixture of different intervention strategies, therefore no single strategy showed superior efficacy.

\section{B A C K G R O U N D}

Smoking is a major risk factor for coronary heart disease (CHD). Compared to non-smokers the odds ratio (OR) for myocardial infarction is about 2.5, and for cardiovascular disorders overall the OR is about 2 (Cook 1986; Jacobs 1999; Kawachi 1994; Keil 1998; Njolstad 1996; Nyboe 1991; Prescott 1998; Shaper 1985; Tunstall-Pedoe 1997; Willett 1987; Woodward 1999). Furthermore after a cardiac event smokers are two times more likely to get restenosis or to die from a cardiovascular disease (Cullen 1997; Fulton 1997; Kawachi 1993; Kawachi 1994; Kuller 1991; Luoto 1998; Tverdal 1993; Willett 1987). A recent systematic review in patients with CHD estimated a reduction in mortality risk of $36 \%$ in 3-5 years after quitting smoking (Critchley 2003). Nonfatal myocardial infarction also occurs less often in smokers who quit after their first cardiac event (OR $0.62,95 \%$ CI 0.46 to 0.83 ) (Barth 2007). However, many smokers do not quit, even after a CHD diagnosis (Critchley 2003), and it is critical to summarise available evidence regarding the effectiveness of different intervention strategies for smoking cessation in this patient group.

Several intervention strategies in healthy people have shown encouraging results in systematic reviews. Simple, brief advice from a physician to quit can increase odds of quitting by over $70 \%$ (OR $1.74,95 \%$ CI 1.48 to 2.05 ) (Lancaster 2004) compared with no intervention. Group behaviour therapy has been shown to double success (OR 1.97, 95\% CI 1.57 to 2.48) (Stead 2005) compared with self-help interventions and is more effective than no intervention. One systematic review found that more intense interventions did not improve abstinence rates (Lancaster 2005a), however, another review found that telephone counselling was more effective than less intense interventions such as self-help (Stead 2006). Self-help interventions may increase quit rates compared with no intervention but the effect is likely to be small (Lancaster 2005b), and there is no evidence they have any additional effects in combination with counselling.

Rigotti has demonstrated the efficacy of smoking cessation interventions for hospitalised patients and stressed the importance of at least one follow-up contact to maintain abstinence (Rigotti 2007). Another review showed that nursing interventions resulted in improved abstinence rates compared with no intervention (Rice 2004), and showed comparable results in hospitalized and healthy people. These various treatment strategies can be summarised as psychosocial interventions and can be differentiated from psychopharmacological or substance replacement treatment strategies (e.g. antidepressants, nicotine replacement). A recent review in patients with chronic obstructive pulmonary disorders did not find a beneficial effect of psychosocial interventions on smoking abstinence, but few studies were included (van der Meer 2001). A recent review of smoking cessation interventions in CHD patients did not find any benefits. However, this review included only 12 studies, which had been previously included in published systematic reviews (Wiggers 2003). Although both psychosocial $(\mathrm{n}=10)$ and pharmacological interventions $(n=2)$ were included, literature searching was not comprehensive. Integration of the studies was descriptive simply counting positive and negative results and the review was unable to assess possible dose-response relationships or influence of study quality. For cardiac patients, psychosocial interventions to quit smoking are recommended along with nicotine replacement therapies and bupropion (ACC/AHA 2002; DeBacker 2003; Ockene 1997). Yet, there is no clear evidence that psychosocial interventions in patients with CHD are efficacious, whether more intense interventions improve quit rates, or which components of intervention programs result in better abstinence rates.

\section{O B JEC T IVES}

This review aimed to evaluate psychosocial intervention strategies for smoking cessation in patients with coronary heart disease, with four specific objectives.

1. To examine the efficacy of psychosocial interventions for smoking cessation in patients with coronary heart disease in short term (6 to 12 month follow-up) and long term (more than 12 months). 2. To compare different psychosocial intervention types (e.g. telephone support) to stop smoking in patients with coronary heart disease.

3. To assess the dose-response relationship: Are brief interventions as effective as more intense interventions?

4. To examine methodological criteria which may moderate the efficacy of smoking cessation interventions in patients with coronary heart disease (validation versus self-report of abstinence). 


\section{CRITERIA FOR CONSIDERING STUDIES FOR THIS REVIEW}

\section{Types of studies}

We included randomised controlled trials studying the efficacy of psychosocial interventions for smoking cessation in CHD patients with an assessment of study outcome at least 6 months after baseline assessment of smoking status. Acceptable study designs were:

a) psychosocial interventions to no such interventions;

b) psychosocial interventions to other psychosocial interventions; and

c) psychosocial interventions to the same psychosocial interventions of different intensity.

\section{Types of participants}

Patients with CHD - myocardial infarction, coronary artery bypass surgery, percutaneous transluminal coronary angioplasty (International Classification of Diseases 9 codes 410-414). Studies including patients with other diseases were accepted, provided at least $80 \%$ of patients had CHD. CHD patients with other comorbidities were included if the diagnosis of CHD was proven. Patients had to be smokers at baseline. Initial smoking status was assessed either by self-report or by additional validation measures. Hospital populations with mixed somatic events (for example pulmonary diseases and cancer) were excluded. Trials were also excluded if there was not sufficient information available about the patient's somatic diagnoses.

\section{Types of intervention}

The psychosocial intervention could be provided in two ways; either as a separate psychosocial intervention with a main focus on smoking cessation or as a part of a more comprehensive cardiac rehabilitation programme addressing also other risk factors also (such as diet). Any psychosocial intervention with the goal to change smoking behaviour in CHD patients was of interest. If the intervention strategy was solely based on a pharmacological or a nicotine replacement approach, the study was excluded. Interventions could be delivered initially during hospital admission or after hospital admission to ex-patients. The interventions may be provided in group or individual settings. Interventions that incorporated counselling, support and advice, with or without provision of written materials were included.

\section{Types of outcome measures}

Abstinence by self-report or validated (e.g. carbon monoxide) measurement at a minimum of 6 months. The outcome is dichotomous (abstinent versus smoking). We did not extract data on the number of cigarettes smoked per day, as there is little evidence that smoking reduction alters the risk of future cardiac events or mortality.

\section{SEARCH METHODSFOR IDENTIFICATIONOF TUDIES}

See: Cochrane Heart Group methods used in reviews.

\section{Electronic searches}

We searched the Cochrane Central Register of Controlled Trials (CENTRAL) on The Cochrane Library (issue 2, 2003), EMBASE (until 1998), MEDLINE (1966-2003), PsycINFO (until week 34, 2003), PSYNDEX (1977-June 2003). No limitations were set to randomised controlled trials. The search strategy for CENTRAL on The Cochrane Library is shown below, search strategies for other databases are in additional tables 1 to 4 .

\section{\#1 HEART DISEASES (exp MeSH)} \#2 CORONARY ARTERY BYPASS (exp MeSH)

\#3 angina*

\#4 cabg

\#5 (coronary near bypass*)

\#6 (coronary near disease*)

\#7 MYOCARDIAL INFARCTION (exp MeSH)

\#8 (myocard* near infarct*)

\#9 (heart near infarct*)

$\# 10$ chd

\#11 (heart next disease*)

\#12 (cardiac next disease*)

$\# 13$ acs

$\# 14 \mathrm{ami}$

\#15 (cardiac next inpatient*)

\#16 (cardiac next patient $\left.{ }^{*}\right)$

\#17 (heart next patient*)

\#18 (heart next inpatient*)

$\# 19$ (\#1 or \#2 or \#3 or \#4 or \#5 or \#6 or \#7 or \#8 or \#9)

$\# 20$ (\#10 or \#11 or \#12 or \#13 or \#14 or \#15 or \#16 or \#17 or $\# 18)$

\#21 (\#19 or \#20)

\#22 SMOKING CESSATION (exp MeSH)

\#23 (smoking near cessation)

\#24 (smoking near cease*)

\#25 (smoking near quit*)

\#26 antismoking

\#27 (anti next smoking)

\#28 (smoking near giv*)

\#29 (smoking near stop*)

$\# 30$ (\#22 or \#23 or \#24 or \#25 or \#26 or \#27 or \#28 or \#29)

\#31 (\#21 and \#30)

Additionally we searched all databases on The Cochrane Library for reviews on smoking cessation

\section{Handsearching}

We searched for trials included in other reviews (Lancaster 2005a; Rigotti 2007; Stead 2005; Stead 2006; Wiggers 2003) and hand-searched relevant journals from 1998 to 2003 (Annals of Internal Medicine, Archives of Internal Medicine, British 
Medical Journal, Psychology and Health, Health Psychology, Tobacco Control). Additionally we looked through the reference lists of the initially identified trials. We asked experts from the German Statusconference on Psychocardiology for information on other trials (see http://portal.uni-freiburg.de/psychokardio/). We did not search for ongoing studies, abstracts, and unpublished studies.

\section{METHODSOF THEREVIEW}

\section{Data extraction and coding}

Data were independently extracted by two people (JBA and Corina Güthlin). Data on setting, CHD diagnosis or procedure, number of subjects, sex, age, and length of follow up were extracted. Five types of interventions were coded; behavioural therapeutic approaches $(\mathrm{BT})$; phone support $(\mathrm{Ph})$; additional selfhelp intervention $(\mathrm{SH})$; multi-risk factor interventions (MR); specific interventions for smoking cessation (see Charactersitics of included studies table).

\section{Treatment duration}

We assessed duration of treatment as in another review (Rigotti 2007) and coded this as follows:

1) Single initial contact lasting $<=1$ hour, no follow-up support; 2) One or more contacts in total $>1$ hour, no follow-up support; 3) Any initial contact plus follow-up $<=1$ month;

4) Any initial contact plus follow-up $>1$ month and $<=6$ month; and

5) Any initial contact plus follow-up $>6$ month.

\section{Methodological quality}

We coded biochemical validation of smoking status as $0=$ no and $1=y e s$; this validated assessment of abstinence was a very relevant methodological aspect of included studies.

Quality of randomisation and allocation concealment was not coded because of lack of data in most of the trials.

\section{Data analysis}

We analysed data on both an intention-to-treat (ITT) and a follow-up basis. A conservative model classified persons without information about smoking status at follow-up as smokers (ITT analysis). A second model included only participants with followup information on smoking status. The latter model results in higher rates of abstinence in experimental and control group (termed 'optimistic model'). We present data of the conservative analysis (ITT) in preference, and only used data from the optimistic model if the ITT analysis was not possible. As a sensitivity analysis, we performed meta-analysis only including those trials where we could calculate the more conservative ITT analysis. We performed three sub-group analyses:

- Trials with validated smoking status at follow-up were compared to non-validated trials.
- Trials grouped by type of intervention.

- Trials with a treatment duration of less than 1 month versus studies with an intervention of 1 month or more.

Odds ratios with $95 \%$ confidence intervals were calculated for the pooled estimates. An OR > 1 indicates superiority of the intervention group over usual care and vice versa. Heterogeneity was assessed by examining forest plots of trials, by calculating chi squared heterogeneity test, and $\mathrm{I}^{2}$ statistics. The chi squared value tests for statistically significant heterogeneity between trials; higher $\mathrm{I}^{2}$ values indicate greater variability between trials than would be expected by chance alone (range 0-100\%) (Higgins 2003). A random-effects model for pooling the studies was employed because of expected heterogeneity in the primary studies (DerSimonian and Laird method) (Deeks 1999). Significant chi squared values indicate heterogeneity and therefore the pooled effect sizes must be interpreted with caution.

\section{DESCRIPTIONOFSTUDIES}

The combination of the hits in the databases searched and additional citations found by scanning references in relevant Cochrane Reviews, other meta-analyses, and journals resulted in 2012 hits. After exclusions on the basis of title and abstract, 520 papers were assessed for inclusion. Of these only 241 studied an intervention for smoking cessation in cardiac patients. First we excluded all studies without a randomised controlled design $(n=145)$. For the exclusion of other non-relevant studies $(n=71)$ the reason for exclusion is detailed in the characteristics of excluded studies table. A further three studies were excluded using post hoc exclusion criteria. Feeney 2001 had a drop out $>50 \%$ of randomised patients (OR 48.17 95\% CI 6.42 to 361.51); Lisspers 1999 was excluded because assessment of smoking status was made after cardiac procedure had been performed, which risks confounding non-smokers with those who quit around the time of the procedure (OR 24.20, 95\% CI 0.93 to 629.32); and Mitsibounas 1992 reported a statistically significant difference in patient characteristics (age/sex) between the intervention and control groups at baseline (OR 16.00, 95\% CI 2.73 to 93.62). Four papers are awaiting assessment as we could not access the papers (Becker 2003; Boulay 2001; EnriquezPuga 2001; Puente-Silva 1989).

The remaining 18 reports of 16 trials were included in the review (Allen 1996; Burt 1974; Carlsson 1997; CASIS 1992; DeBusk 1994; Dornelas 2000; Hajek 2002; Heller 1993; Ortigosa 2000; Quist-Paulsen 2003; Reid 2003; Rigotti 1994; Sivarajan 1983; Taylor 1990; van Elderen (group); van Elderen (phone)). Seven studies were carried out in Europe (1 Sweden, 2 United Kingdom, 2 Netherlands, 1 Norway, 1 Spain), seven were from the USA, one from Australia and one from Canada. The papers were mainly published in English (15), one was written in Spanish (Ortigosa 2000). All trials compared a specific smoking cessation intervention with 
a usual care condition, had comparable groups at study entry, had lower than 50\% drop out rates and assessed smoking status before a cardiac event or procedure. 1323 patients were randomised to the usual care group and 1354 received a special psychosocial intervention. As expected, 70 to $90 \%$ of the patients were male, mean age was relatively young, 50 to 60 years. The patients suffered predominantly from myocardial infarction or had invasive interventions (bypass surgery, stent). The intervention strategies employed were behavioural therapeutic interventions (10 studies), and self-help programmes (11 studies). Additional phone support was provided in 11 trials. Nine studies reported interventions aimed specifically at smoking cessation, seven studies employed multi-risk strategies. Behavioural therapeutic interventions were either provided in a group setting or as individual counselling. The aim was to identify cues related to smoking, or more generally stress reduction and relaxation techniques. Other components included preparation for relapse or specific motivational techniques based on the transtheoretical model (Prochaska 1986) or the strategy of motivational interviewing (Rollnick 1997). Self-help interventions consisted of information booklets, audio- or videotapes. Information booklets which simply described risk factors were not considered self-help interventions. No studies were available for the comparison of different psychosocial interventions or of psychosocial intervention with different intensity.

\section{METHODOLOGICALQUALITY}

All studies assessed abstinence 12 months after the initial intervention, except two (Heller 1993; Sivarajan 1983), which assessed abstinence after 6 months. Two trials also provided data on a longterm follow up after 5 years (CASIS 1992; Rigotti 1994). Seven of the 16 trials validated self-reported abstinence. In five trials data for the 'optimistic model' was reported $(n=462), 11$ trials provided sufficient data for an ITT analysis $(\mathrm{n}=2215)$. Unfortunately, it was impossible to extract detailed information on the randomisation procedure from most of the trials. Only four trials used adequate allocation concealment (Allen 1996; Dornelas 2000; Hajek 2002; Reid 2003).

\section{RES U L T S}

Psychosocial smoking cessation interventions were effective in achieving smoking abstinence in CHD patients, compared with usual care. In all trials, patients receiving the specific psychosocial intervention had more than a $60 \%$ higher odds of quitting (OR $1.66,95 \%$ CI 1.25 to 2.22 ). There was considerable heterogeneity between individual studies ( $\mathrm{chi}^{2} 42.68$; df $15, \mathrm{P}<0.0002, \mathrm{I}^{2}$ $64.9 \%$ ) (comparison 0101 ). Therefore the overall result has to be interpreted with caution. There were considerable differences between trials in the proportion of abstinent patients at follow-up: Taylor 1988 achieved 70\% abstinence in the intervention group but Ortigosa 2000 report the same number of patients abstinent without intervention. Hajek 2002 report the lowest abstinence rates in the patients receiving psychosocial intervention (39\%) and Carlsson 1997 report the lowest values for control group patients (25\%).

The pooled ORs suggest that psychosocial interventions can greatly increase odds of quitting compared with usual care, but the heterogeneity in the results needed further exploration. The quality of the trials may partly explain this heterogeneity. Allocation concealment has been shown empirically to influence trial results (Jüni 2001). Few studies reported adequate allocation concealment. We pooled results for these studies, but results of the combined effect measure must be interpreted with caution, due to the limited statistical power (Allen 1996; Dornelas 2000; Hajek 2002; Reid 2003). The non-significant OR of trials using adequate allocation concealment was 1.10 (95\% CI 0.75 to 1.60 ). The largest trial with adequate allocation concealment was also a brief intervention (Hajek 2002), which we found not to be effective (comparison 0102 ). The pooled OR for allocation concealed trials appears lower than for all trials, but due to limited number of studies it is impossible to assess whether this is due to higher quality (allocation concealment), or the brevity of the intervention.

Sensitivity analysis of only trials using ITT analysis showed less benefit than all trials combined, but remained clinical important (nearly a 50\% increase in odds of quitting) and statistically significant (OR 1.47, 95\% CI 1.10 to 1.96 ) but considerable heterogeneity remained $\left(\mathrm{chi}^{2} 25.27\right.$, df $10, \mathrm{P}<0.005, \mathrm{I}^{2}$ 60.4\%) (comparison 0103 ).

\section{Sub-group analyses \\ Trials validating smoking status}

Trials which validated self-reported smoking status showed lower quit rates than trials where measurement was not validated. If trials with validated abstinence are pooled, the OR falls from 1.92 (95\% CI 1.26 to 2.93 ) for non-validated trials to 1.44 (95\% CI 0.99 to 2.11) for validated measures (comparison 0201 ).

\section{Types of intervention}

We found no clear evidence that any treatment strategy was more efficacious than others, but heterogeneity was reduced within the intervention cluster. Behavioral therapeutic interventions showed a significant effect on abstinence (OR 1.69, 95\% CI 1.33 to 2.14) with lower heterogeneity ( $\left.\mathrm{I}^{2} 23.5 \%\right)$ (comparison 0301 ). Telephone support was also effective (OR $1.58,95 \%$ CI 1.28 to 1.97 ) and trials reasonably consistent ( $\mathrm{I}^{2} 9.9 \%$ ) (comparison 0302 ). However, as most behavioural therapy trials also used telephone support as an intervention strategy, it is difficult to separate the effects of these two types of interventions. Two trials used solely a behavioural therapeutic approach without additional phone contacts (Sivarajan 1983; van Elderen (group)). One trial used telephone support without behavioural therapeutic techniques (Ortigosa 2000). Interventions using self-help materials showed com- 
parable effectiveness (OR 1.48, 95\% CI 1.11 to 1.96 ) (comparison 03 03). Stratification of trials using self-help materials reduced heterogeneity only slightly $\left(\mathrm{I}^{2} 56.2 \%\right)$. We also considered the specificity of the intervention (smoking cessation alone compared with a multi-risk factor intervention). No difference was found between multi-risk factor interventions (OR 1.73, 95\% CI 1.27 to 2.35 ) and specific cessation intervention (OR 1.63, 95\% CI 1.08 to 2.46) (comparison 0304 ). While the heterogeneity in specific intervention trials increased $\left(\mathrm{I}^{2} 77.8 \%\right)$ the results of multi-risk factor intervention trials were statistically homogenous $\left(\mathrm{I}^{2} 0 \%\right)$.

\section{Duration of the intervention}

We found clear evidence that brief interventions (i.e. no followup contact or within 4 weeks after initial intervention) were not effective (Hajek 2002; Heller 1993; Ortigosa 2000; Rigotti 1994) (OR 0.92 , 95\% CI 0.70 to $1.22, \mathrm{I}^{2} 0 \%$ ) (comparison 0401 ). When CHD patients were treated with interventions including follow-up contacts after the initial period of 1 month, the odds of quitting increased substantially (OR $1.98,95 \%$ CI 1.49 to $2.65, \mathrm{I}^{2}$ $50.3 \%$ ) (comparison 0401 ). There was less heterogeneity between trial results when clustered by intensity of the intervention.

\section{Long-term follow-up}

We found no evidence for efficacy of smoking cessation interventions in the long-term. Due to high drop-out rates after 5 years, an analysis for people available at follow-up and an ITT analysis were performed. Neither the optimistic model (OR 1.32, 95\% CI 0.78 to 2.24 ) nor the ITT analysis (OR 1.23 , 95\% CI 0.79 to 1.93 ) showed superior efficacy to a control group (comparisons 0501 and 0502 , respectively).

A potential problem with all systematic reviews is publication bias. Our literature search was comprehensive, prepared and partly carried out by the Cochrane Heart Group (UK). Additionally, we investigated publication bias using a funnel plot. The results appear reasonably symmetric which is an indicator of a publication of the studies independent of the study result (Figure 01). There may be a slight tendency for larger trials to show smaller benefits; but larger studies may have interventions with shorter duration and hence smaller effect sizes.

\section{I S C US S I O N}

We found support for the efficacy of smoking cessation interventions with more than 1 month duration, but brief interventions without some follow-up contact were not effective. We were unable to determine the minimum number of contacts needed. More detailed conclusions about effective intervention strategies are obscured by the fact that a mixture of different intervention measures were included in many trials. Interventions using telephone support, behavioural therapies, and self-help were all effective. Some interventions focussed only on smoking cessation, but others ad- dressed smoking as part of a multiple risk factor intervention programme (generally a 'cardiac rehabilitation programme'). There was no difference in the odds of quitting for multiple risk factor cardiac rehabilitation programmes, compared with interventions focussing only on smoking cessation. 'Cardiac rehabilitation' programmes may vary in their components, but generally include a graded exercise programme and may also include advice and support from a range of health professionals (such as dieticians, behavioural change specialists etc). It is difficult to distinguish between the effects of the smoking cessation component of these programmes, and the general support and encouragement that may be given by other health professionals. Some trials employ nicotine replacement therapy (NRT) as additional cessation strategies, which we could not control for. In one trial, more patients in the psychosocial intervention group received NRT compared to the usual care group (DeBusk 1994). Other trials did not report use of NRT.

Our findings are contrary to a recently published review on smoking cessation interventions in CHD patients which found no benefits (Wiggers 2003). The difference may be due to more comprehensive literature searching in our review, whereas Wiggers et al aggregated 12 primary studies listed in already existing Cochrane reviews. Another difference is the methodology of the reviews. Wiggers et al counted 'positive' and 'negative' results, whereas we performed a meta-analytic pooling. The important advantage of a meta-analytic approach is the weighting of studies by sample size and event rate.

One possible threat to our results might be methodological flaws in the primary studies. Validation of abstinence was reported in primary studies, and associated with lower efficacy. The OR of quitting in validated trials was only of borderline statistical significance; however these validated trials also included many with only a brief intervention. Despite the high validity of self reported smoking status in the general population (Patrick 1994) the validation of smoking status should be recommended in efficacy trials with coronary heart disease patients (Woodward 1992).

\section{AUTHORS, CONCLUSIONS}

\section{Implications for practice}

After a cardiac event about $30 \%$ to $50 \%$ of smokers with CHD quit without professional help. Additional psychosocial interventions show a superior quitting rate compared to standard care. Interventions for smoking cessation in CHD patients should last for more than 1 month. Brief interventions may not be effective. The overall effect of psychosocial smoking cessation interventions in CHD patients can be expressed by the number needed to treat statistics with a figure of 9.7. This means about 10 patients had to be treated for one person to be abstinent from tobacco after 1 year. 


\section{Implications for research}

Trial procedures and quality should be described in more detail, according to CONSORT guidelines (Begg 1996). Also more details on the duration and intensity of the intervention (total duration, number of sessions, numbers of pages in leaflets etc) are needed. The validation of smoking status was not a standard procedure in the trials as only seven described using any measure of biochemical validation. Further trials should validate smoking status objectively.

Studies comparing different psychosocial interventions or psychosocial intervention of different intensity are lacking. Hence future research should focus on the comparison of different smoking cessation strategies in CHD patients (Schmitz 1999). It is still unclear whether individual counseling or group counseling are more beneficial in CHD patients. Also recent results of reviews show limited effects of stage based smoking cessation interventions (Riemsma 2003; vanSluis 2004). More detailed studies will be useful to identify components of successful intervention strategies. This approach will require fewer studies but with larger sample sizes to demonstrate relatively small, but clinically important differences between strategies. Future trials should compare the additional benefits of combining NRT and psychosocial rehabilitation, compared with NRT or psychosocial interventions alone.

\section{NOTES}

Used abbreviations

AMI: acute myocardial infarction

$\mathrm{AP}$ : angina pectoris

BIOSIS: Database on life science and biomedical research (www.biosis.org)

CABG: coronary artery bypass graft

CHD: coronary heart disease

$\mathrm{CI}$ : confidence interval

EMBASE: Database with biomedical and pharmacological information (www.embase.com)

ICD: International Classification of Diseases
ITT: Intention to treat analysis

Medline: database of the U.S. National Library of Medicine

MI: myocardial infarction

$\mathrm{MeSH}$; Medical subject heading

$\mathrm{N}$ : Number of studies

$\mathrm{n}$ : Number of patients

OR: Odds ratio

OM: Optimistic model

PsycINFO: database of the American Psychological Association PSYNDEX: database of the Center for Psychological Information and Documentation at the University of Trier, Germany PTCA: percutaneous transluminal coronary angioplasty

\section{POTENTIALCONFLICTOF I N T E R E S T}

None known.

\section{ACKNOWLEDGEMENTS}

We would like to thank for the support of the Cochrane Heart Group, especially Theresa Moore, Margaret Burke and Shah Ebrahim for comments on the protocol of our review and assistance in literature search. Many thanks to Corina Güthlin for her assistance in extracting the data and Simon Capewell for advice on the manuscript.

\section{SOURCES OF SUPPORT}

\section{External sources of support}

- No sources of support supplied

Internal sources of support

- Department of Rehabilitation Psychology GERMANY

- Wissenschaftliche Gesellschaft University of Freiburg GERMANY

\section{R E F E R E N C E S}

\section{References to studies included in this review}

Allen 1996 \{published data only\}

Allen JK. Coronary risk factor modification in women after coronary artery bypass surgery. Nursing Research 1996;45(5):260-5.

Burt 1974 \{published data only\}

Burt A, Thornley R, Illingworth D, White P, Shaw TR, Turner R. Stopping smoking after myocardial infarction. Lancet 1974;1(7852): $304-6$.
Carlsson 1997 \{published data only\}

Carlsson R, Lindberg G, Westin L, Israelsson B. Influence of coronary nursing managment follow up on lifestyle after acute myocardial infarction. Heart 1997;77(3):256-9.

CASIS 1992 \{published data only\}

* Ockene J, Kristeller JL, Goldberg R, Ockene I, Merriam P, Barrett S, et al. Smoking cessation and severity of disease: the Coronary Artery Smoking Intervention Study. Health Psychology 1992;11(2):119-26.

Rosal MC, Ockene JK, Ma Y, Hebert JR, Ockene IS, Merriam P,

Psychosocial interventions for smoking cessation in patients with coronary heart disease (Review)

Copyright $(2008$ The Cochrane Collaboration. Published by John Wiley \& Sons, Ltd 
Hurley TG. Coronary artery smoking intervention study (CASIS): 5-year follow up. Health Psychology 1998;17(5):476-8.

DeBusk 1994 \{published data only\}

DeBusk R, Miller NH, Superko R, Dennis CA, Thomas RJ, et al. A case-management system for coronary risk factor modification after acute myocardial infarction. Annals of Internal Medicine 1994;120 (9):721-9.

Dornelas 2000 \{published data only\}

Dornelas EA, Sampson RA, Gray J F, Waters D, Thompson PD. A randomized controlled trial of smoking cessation counseling after myocardial infarction. Preventive Medicine 2000;30(4):261-8.

Hajek 2002 \{published data only\}

Hajek P, Taylor TZ, Mills P. Brief intervention during hospital admission to help patients to give up smoking after myocardial infarction and bypass surgery: randomised controlled trial. BMJ 2002;324: 87-9.

Heller 1993 \{published data only\}

Heller RF, Knapp JC, Valenti LA, Dobson AJ. Secondary prevention after acute myocardial infarction. American Journal of Cardiology 1993;72(11):759-62.

Ortigosa 2000 \{published data only\}

Moreno Ortigosa A, Ochoa Gomez FJ, Ramalle-Gomara E, Saralegui Reta I, Fernandez Esteban MV, Quintana Diaz M. Efficacy of an smoking cessationg intervention for patients with myocardial infarction [Eficacia de una intervencion para dejar de fumar en pacientes con infarto de miocardio]. Medicina Clinica 2000;114:209-10.

Quist-Paulsen 2003 \{published data only\}

Quist-Paulsen P, Gallefoss F. Randomised controlled trial of smoking cessation intervention after admission for coronary heart disease. BMJ 2003;327(7426):1254-7.

Reid 2003 \{published data only\}

Reid R, Pipe A, Higginson LK, D’Angelo MS, Cooke D, Dafoe W. Stepped care approach to smoking cessation in patients hospitalized for coronary artery disease. Journal of Cardiopulmonary Rehabilitation 2003;23(3):176-82.

Rigotti 1994 \{published data only\}

Rigotti NA, McKool KM, Shiffmann S. Predictors of smoking cessation after coronary artery bypass graft surgery. Annals of Internal Medicine 1994;120(4):287-93.

Sivarajan 1983 \{published data only\}

Sivarajan ES, Newton KM, Almes MJ, Kempf TM, Mansfield LW, Bruce RA. Limited effects of outpatient teaching and counseling after myocardial infarction: a controlled study. Heart \& Lung 1983;12(1): $65-73$.

Taylor 1990 \{published data only\}

Taylor CB, Houston-Miller N, Killen JD, DeBusk RF. Smoking cessation after acute myocardial infarction: effects of a nurse-managed intervention. Annals of Internal Medicine 1990;113(2):118-23.

van Elderen (group) \{published data only\}

Van Elderen T, Maes S, Seegers G. Effects of a group health education program for coronary heart patients after the hospitalization phase. Tijdschrift voor Psychologie \& Gezondheid 1991;19(3):129-44.

Van Elderen T, Maes S, Seegers G. Effects of a post-hospitalization group health education programme for patients with coronary heart disease. Psychology and Health 1994;9(4):317-30. van Elderen (phone) \{published data only\} van Elderen-van Kemenade T, Maes S, van den Broek Y. Effects of a health education programme with telephone follow-up during cardiac rehabilitation. British Journal of Clinical Psychology 1994;33 (Pt 3):367-78.

\section{References to studies excluded from this review}

Andersen 2002

Andersen LB, Klausen K, Nisbeth O. One-year effect of health counseling on life style and risk factors of heart disease [Et ars effekt af sundhedsvejledning pa livsstil og risikofaktorer for hjertesygdom]. Ugeskrift for Laeger 2002;164(13):1814-8.

\section{Baughman 1982}

Baughman Kl, Hutter AMJ, DeSanctis RW, Kallman CH. Early discharge following acute myocardial infarction. Long-term follow-up of randomized patients. Archives of Internal Medicine 1982;142(5): $875-8$.

Belson 2002

Belson MG, Kelley TR. Bupropion exposures: Clinical manifestations and medical outcome. Journal of Emergency Medicine 2002;23 (3):223-30

\section{Bolman 2002}

Bolman C, de Vries H, van Breukelen G. Evaluation of a nursemanaged minimal-contact smoking cessation intervention for cardiac inpatients. Health Education Research 2002;17(1):99-116.

\section{Brenner 1989}

Brenner H. Sekundärprävention bei Herzinfarktpatienten. Report Psychologie 1989;14(9):26-34.

\section{Byfield 2001}

Byfield CL. Development and evaluation of a lifestyle physical activity intervention for obese sedentary women. Colorado State University PhD Thesis 2001.

\section{Campbell 1996}

Campbell IA, Prescott RJ, Tjeder-Burton SM. Transdermal nicotine plus support in patients attending hospital with smoking-related diseases: a placebo-controlled study. Respiratory Medicine 1996;90(1): $47-51$.

\section{Campbell 1998a}

Campbell NC, Ritchie LD, Thain J, Deans HG, Rawles JM, Squair JL. Secondary prevention in coronary heart disease: A randomised trial of nurse led clinics in primary care. Heart 1998;80(5):447-52.

\section{Campbell 1998b}

Campbell NC, Thain J, Deans HG, Ritchie LD, Rawles JM, Squair JL. Secondary prevention clinics for coronary heart disease: randomised trial of effect on health. BMJ 1998;316:1434-37.

\section{Circo 1985}

Circo A, Tosto A, Raciti S. First results of an anti-smoke outpatient unit: Comparison among three methods [Primi risultati di un ambulatorio anti-fumo. Confronto fra tre metodiche]. Rivista di Cardiologia Preventiva e Riabilitativa 1985;3:147-51.

\section{Connett 1984}

Connett JE, Stamler J. Responses of black and white males to the special intervention program of the Multiple Risk Factor Intervention Trial. American Heart Journal 1984;108(3 Pt 2):839-48. 
Cook 1989

Cook DG, Shaper AG. Stopping smoking and risk of ischaemic heart disease. Lancet 1989;1(8643):895.

Cupples 1999

Cupples ME, McKnight A. Five year follow up of patients at high cardiovascular risk who took part in randomised controlled trial of health promotion. BMJ 1999;319:687-8.

Eaker 1982

Eaker ED, Benfari RC, Reed RB. Coronary risk factor intervention: characteristics associated with change. Journal of Clinical Psychology 1982;38(4):703-17.

Engblom 1992

Engblom E, Rönnemaa T, Hämäläinen H, Kallio V, Vänttinen E, Knuts L-R. Coronary heart disease risk factors before and after bypass surgery: results of a controlled trial on multifactorial rehabilitation. European Heart Journal 1992;13:232-7.

\section{Erdman 1983}

Erdman RA, Duivenvoorden HJ. Psychologic evaluation of a cardiac rehabilitation program: A randomized clinical trial in patients with myocardial infarction. Journal of Cardiac Rehabilitation 1983;3:696701.

Feeney 2001

Feeney GF, McPherson A, Connor JP, McAlister A, Young Rm, Garrahy $\mathrm{P}$. Randomized controlled trial of two cigarette quit programmes in coronary care patients after acute myocardial infarction. Internal Medicine Journal 2001;31(8):470-5.

Finnegan 1985

Finnegan DL, Suler JR. Psychological factors associated with maintenance of improved health behaviors in postcoronary patients. Journal of Psychology 1985;119(1):87-94.

\section{Fletcher 1987}

Fletcher V. An individualized teaching programme following primary uncomplicated myocardial infarction. Journal of Advanced Nursing 1987;12(2):195-200.

\section{Fortmann 1994}

Fortmann SP. Nicotine replacement therapy for patients with coronary artery disease. Working Group for the Study of Transdermal Nicotine in Patients with Coronary artery disease. Archives of Internal Medicine 1994;154:989-95.

Frasure-Smith 1997

Frasure-Smith N, Lesperance F, Prince RH, Verrier P, Garber RA, Juneau M, et al. Randomised trial of home-based psychosocial nursing intervention for patients recovering from myocardial infarction. Lancet 1997;350(9076):473-9.

\section{Fredrickson 1995}

Fredrickson PA, Hurt RD, Lee GM, Wingender L, Croghan IT, Lauger $G$, et al. High dose transdermal nicotine therapy for heavy smokers: safety, tolerability and measurement of nicotine and cotinine levels. Psychopharmacology 1995;122(3):215-22.

\section{Hall 1983}

Hall SM, Bachman J, Henderson JB, Barstow R, Jones RT. Smoking cessation in patients with cardiopulmonary disease: An initial study. Addictive Behaviors 1983;8(1):33-42.

\section{Haskell 1994}

Haskell WL, Alderman EL, Fair JM, Maron DJ, Mackey SF, Superko $\mathrm{HR}$, et al. Effects of intensive multiple risk factor reduction on coronary atherosclerosis and clinical cardiac events in men and women with coronary artery disease. The Stanford Coronary Risk Intervention Project (SCRIP). Circulation 1994;89(3):975-90.

\section{Hjermann 1986}

Hjermann I, Holme I, Leren P. Oslo Study Diet and Antismoking Trial. Results after 102 months. American Journal of Medicine 1986; 80:7-11.

\section{Horlick 1984}

Horlick L, Cameron R, Firor W, Bhalerao U, Baltzan R. The effects of education and group discussion in the post myocardial infarction patient. Journal of Psychosomatic Research 1984;28(6):485-92.

\section{Houston-Miller 1997}

Miller NH, Smith PM, DeBusk RF, Sobel DS, Taylor CB. Smoking cessation in hospitalized patients: Results of a randomized trial. Archives of International Medcine 1997;157:409-15.

\section{Jones 1996}

Jones DA, West RR. Psychological rehabilitation after myocardial infarction multicentre randomised controlled trial. BMJ 1996;313 (7071):1517-21.

\section{Joseph 1996}

Joseph AM, Norman SM, Ferry LH, Prochazka AV, Westman EC, Steele BG, et al. The safety of transdermal nicotine as an aid to smoking cessation in patients with cardiac disease. New England Journal of Medicine 1996;335(24):1792-8.

\section{Kallio 1981}

Kallio V, Hämäläinen H, Arstila M, Luurila OJ, Hakkila J. Systematic treatment after acute myocardial infarction. Suomen Lääkärilehti 1981;36:1975-82.

\section{Knutsen 1991}

Knutsen SF, Knutsen R. The Tromso Survey: the Family Intervention study--the effect of intervention on some coronary risk factors and dietary habits, a 6-year follow-up. Preventive Medicine 1991;20(2): 197-212.

\section{Kornitzer 1980}

Kornitzer M, Dramaix M, Kittel F, De Backer G. The Belgian Heart disease Prevention Project: Changes in smoking habits after two years of intervention. Preventive Medicine 1980;9(4):496-503.

\section{Kornitzer 1989}

Kornitzer M. The Belgian project for the prevention of cardiovascular diseases: a model of multifactorial prevention [Le projet belge de prevention des affections cardiovasculaires: un modele de prevention multifactorielle]. Bulletin et Memoires de l Academie Royale de Medecine de Belgique 1989;144(1-2):101-9.

\section{Kristeller 1993}

Kristeller JL, Merriam PA, Ockene JK, Ockene IS, Goldberg RJ. Smoking intervention for cardiac patients: in search of more effective strategies. Cardiology 1993;82(5):317-24.

\section{Kuller 1991}

Kuller LH, Ockene JK, Meilahn E, Wentworth DN, Svendsen KH, Neaton JD. Cigarette smoking and mortality. MRFIT Research Group. Preventive Medicine 1991;20(5):638-54. 


\section{Lancaster 1999}

Lancaster T, Dobbie W, Vos K, Yudkin P, Murphy M, Fowler G. Randomized trial of nurse-assisted strategies for smoking cessation in primary care. British Journal of General Practice 1999;49(440):19194.

\section{Lisspers 1999}

Lisspers J, Sundin Ö, Hofman-Bang C, Nordlander R, Nygren A, Ryden L, et al. Behavioral effects of a comprehensive, multifactorial program for lifestyle change after percutaneous transluminal coronary angioplasty: a prospective, randomized, controlled study. Journal of Psychosomatic Research 1999;46(2):143-54.

\section{Marra 1985}

Marra S, Paolillo V, Spadaccini F, Angelino PF. Long-term follow-up after a controlled randomized post-myocardial infarction rehabilitation programme: effects on morbidity and mortality. European Heart Journal 1985;6(8):656-63.

\section{Mayou 2002}

Mayou RA, Thompson DR, Clements A, Davies CH, Goodwin SJ, Normington K, Hicks N, Price J. Guideline-based early rehabilitation after myocardial infarction. A pragmatic randomised controlled trial. Journal of Psychosomatic Research 2002;52(2):89-95.

\section{McHugh 2001}

McHugh F, Lindsay GM, Hanlon P, Hutton I, Brown MR, Morrison $\mathrm{C}$, et al. Nurse led shared care for patients on the waiting list for coronary artery bypass surgery: A randomised controlled trial. Heart 2001;86(3):317-23.

\section{Meland 1999}

Meland E, Maeland JG, Laerum E. The importance of self-efficacy in cardiovascular risk factor change. Scandinavian Journal of Public Health 1999;27(1):11-7.

\section{Mitsibounas 1992}

Mitsibounas DN, Tsouna-Hadjis ED, Rotas VR, Sideris DA. Effects of group psychosocial intervention on coronary risk factors. $P s y$ chotherapy \& Psychosomatics 1992;58(2):97-102.

\section{Murchie 2003}

Murchie P, Campbell NC, Ritchie LD, Simpson JA, Thain J. Secondary prevention clinics for coronary heart disease: Four year follow up of a randomised controlled trial in primary care. BMJ 2003;326 (7380):84-7.

\section{Nisbeth 2000}

Nisbeth O, Klausen K, Andersen LB. Effectiveness of counselling over 1 year on changes in lifestyle and coronary heart disease risk factors. Patient Education \& Counseling 2000;40(2):121-31.

\section{Ornish 1990}

Ornish D, Brown SE, Scherwitz LW, Billings JH, Armstrong WT, Ports TA, et al. Can lifestyle changes reverse coronary heart disease? The Lifestyle Heart Trial. Lancet 1990;336(8708):129-33.

\section{Patel 1985}

Patel C, Marmot MG, Terry DJ, Carruthers M, Hunt B, Patel M. Trial of relaxation in reducing coronary risk: four year follow up. British Medical Journal Clinical Research Ed 1985;290(6475):11036.

\section{Prieme 1998}

Prieme H, Nyyssonen K, Gronbaek K, Klarlund M, Loft S, Tonnesen P, Salonen JT, et al. Randomized controlled smoking cessation study:
Transient increase in plasma high density lipoprotein but no change in lipoprotein oxidation resistance. Scandinavian Journal of Clinical and Laboratory Investigation 1998;58(1):11-18.

Rice 1994

Rice VH, Fox DH, Lepczyk M, Sieggreen M, Mullin M, Jarosz P, et al. A comparison of nursing interventions for smoking cessation in adults with cardiovascular health problems. Heart \& Lung 1994;23 (6):473-86

\section{Risser 1990}

Risser NL, Belcher DW. Adding spirometry, carbon monoxide and pulmonary symptom results to smoking cessation couseling: a randomized trial. Journal of General Internal Medicine 1990;5(1):16-22.

\section{Rose 1978}

Rose G, Hamilton PJ. A randomised controlled trial of the effect on middle-aged men of advice to stop smoking. Journal of Epidemiology \& Community Health 1978;32(4):275-81.

Rose 1982

Rose G, Hamilton PJ, Colwell L, Shipley MJ. A randomised controlled trial of anti-smoking advice: 10-year results. Journal of Epidemiology \& Community Health 1982;36:102-8.

\section{Rose 1992}

Rose G, Colwell L. Randomised controlled trial of anti-smoking advice: final (20 year) results. Journal of Epidemiology \& Community Health 1992;46(1):75-7.

\section{Sanders 1989}

Sanders D, Fowler G, Mant D, Fuller A, Jones L, Marzillier J. Randomized controlled trial of anti-smoking advice by nurses in general practice. Journal of the Royal College of Physicians of London 1989;39 (324):273-6.

\section{Schmitz 1999}

Schmitz JM, Spiga R, Rhoades HM, Fuentes F, Grabowski J. Smoking cessation in women with cardiac risk: a comparative study of two theoretically based therapies. Nicotine \& Tobacco Research 1999;1(1): 87-94.

Simon 2003

Simon JA, Carmody TP, Hudes ES, Snyder E, Murray J. Intensive smoking cessation counseling versus minimal counseling among hospitalized smokers treated with transdermal nicotine replacement: A randomized trial. American Journal of Medicine 2003;114(7):55562.

\section{Sippel 1999}

Sippel JM, Osborne ML, Bjorson W, Goldberg B, Buist AS. Smoking cessation in primary care clinics. Journal of General Internal Medicine 1999;14(11):670-6.

\section{Steptoe 1999}

Steptoe A, Doherty S, Rink E, Kerry S, Kendrick T, Hilton S. Behavioural counselling in general practice for the promotion of healthy behaviour among adults at increased risk of coronary heart disease: Randomised trial. BMJ 1999;319(7215):943-7.

\section{Steptoe 2001}

Steptoe A, Kerry S, Rink E, Hilton S. The impact of behavioral counseling on stage of change in fat intake, physical activity, and cigarette smoking in adults at increased risk of coronary heart disease. American Journal of Public Health 2001;91(2):265-9. 


\section{Stewart 1999}

Stewart S, Marley JE, Horowitz JD. Effects of a multidisciplinary, home-based intervention on unplanned readmissions and survival among patients with chronic congestive heart failure: a randomised controlled study. Lancet 1999;354(9184):1077-83.

Suurkula 1996

Suurkula M, Agewall S, Fagerberg B, Wendelhag I, Wikstrand J. Multiple risk intervention in high-risk hypertensive patients. A 3year ultrasound study of intima-media thickness and plaques in the carotid artery. Risk Intervention Study (RIS) Group. Arteriosclerosis, Thrombosis \& Vascular Biology 1996;16(3):462-70.

Taylor 1988

Taylor CB, Houston-Miller N, Haskell WL, Debusk RF. Smoking cessation after acute myocardial infarction: The effects of exercise training. Addictive Behaviors 1988;13(4):331-5.

Taylor 1997

Taylor CB, Houston-Miller N, Smith PM, DeBusk RF. The effects of home-based, case-managed, multifactorial risk-reduction program on reducing psychological distress in patients with cardiovascular disease. Journal of Cardiopulmonary Rehabilitation 1997;17:157-62.

Tiffany 1986

Tiffany ST, Martin EM, Baker TB. Treatments for cigarette smoking: An evaluation of the contributions of aversion and counseling procedures. Behaviour Research \& Therapy 1986;24(4):437-52.

\section{Tonnesen 1999}

Tonnesen P, Paoletti P, Gustavsson G, Russell MA, Saracci R, Gulsvik A, et al. Higher dosage nicotine patches increase one-year smoking cessation rates: Results from the European CEASE trial. European Respiratory Journal 1999;13(2):238-46.

\section{Tonstad 2003}

Tonstad S, Farsang C, Klaene G, Lewis K, Manolis A, Perruchoud AP, et al. Bupropion SR for smoking cessation in smokers with cardiovascular disease: a multicenter randomised study. European Heart Journal 2003;24:946-55.

\section{Toobert 1998}

Toobert DJ, Glasgow RE, Nettekoven LA, Brown JE. Behavioral and psychosocial effects of intensive lifestyle management for women with coronary heart disease. Patient Education \& Counseling 1998; 35(3):177-88.

\section{Toobert 2000}

Toobert DJ, Glasgow RE, Radcliffe JL. Physiologic and related behavioral outcomes from the Women's Lifestyle Heart Trial. Annals of Behavioral Medicine 2000;22(1):1-9.

Tzivoni 1998

Tzivoni D, Keren A, Meyler S, Khoury Z, Lerer T, Brunel P. Cardiovascular safety of transdermal nicotine patches in patients with coronary artery disease who try to quit smoking. Cardiovascular Drugs \& Therapy 1998;12(3):239-44.

\section{Vedin 1976}

Vedin A, Wilhelmsson C, Tibblin G, Wilhelmsen L. The postinfarction clinic in Goteborg, Sweden. A controlled trial of a therapeutic organization. Acta Medica Scandinavica 1976;200(6):453-6.

\section{Wallner 1999}

Wallner S, Watzinger $\mathrm{N}$, Lindschinger $\mathrm{M}$, Smolle KH, Toplak H, Eber B, et al. Effects of intensified lifestyle modification on the need for further revascularization after coronary angioplasty. European Journal of Clinical Investigation 1999;29(5):372-9.

\section{Waters 1996}

Waters D, Lesperance J, Gladstone P, Boccuzzi SJ, Cook T, Hudgin $\mathrm{R}$, et al. Effects of cigarette smoking on the angiographic evolution of coronary atherosclerosis: A Canadian Coronary Atherosclerosis Intervention trial (CCAIT) substudy. Circulation 1996;94:614-21.

\section{Wewers 1994}

Wewers ME, Bowen JM, Stanislaw AE, Desimone VB. A nurse-delivered smoking cessation intervention among hospitalized postoperative patients-influence of a smoking-related diagnosis: A pilot study. Heart \& Lung, 1994. p. Heart \& Lung 1994;23(2):151-6.

\section{Whitlock 1997}

Whitlock EP, Vogt TM, Hollis JF, Lichtenstein E. Does gender affect response to a brief clinic-based smoking intervention? American Journal of Preventive Medicine. American Journal of Preventive Medicine 1997;13(3):159-66

\section{References to studies awaiting assessment}

\section{Becker 2003}

Becker BM, Bock BC, Partridge RA. Smoking cessation interventions in the emergency department for smokers with chest pain. Acadademic Emergency Medicine 2003;10(5):507.

\section{Boulay 2001}

Boulay P, Prud'Homme D. Risk factor management after short-term versus long-term cardiac rehabilitation program. Coronary Health Care 2001;5(3):133-40.

\section{Enriquez-Puga 2001}

Enriquez-Puga A, Khunti K. Secondary prevention of coronary heart disease in primary care. Journal of Clinical Governance 2001;9(4): 211-22.

\section{Puente-Silva 1989}

Puente-Silva FG, Cicero R, Gonzalez E, Ocampo A. Comparative study of four programs for smoking cessation among chronic cardiorespiratory patients [Estudio comparativo de cuatro programas para el abandono del tabaquismo en pacientes cronicos cardiorespiratorios]. Revista Intercontinental de Psicologia y Educacion 1989;2(3) $113-31$

\section{Additional references \\ ACC/AHA 2002}

Braunwald A. ACC/AHA guideline update for the management of patient with unstable angina and non-ST-segment elevation myocardial infarction. A Report of the American College of Cardiology/American Heart Association Task Force on Practice Guidelines (Committee on the Management of Patients With Unstable Angina). Available at: http: //www.americanheart.org/downloadable/heart/1016214837537UANSTEMI2002We [accessed 01/01/2007] Vol. 2002.

Barth 2007

Barth J, Bengel J. Smoking cessation in patients with coronary heart disease: Risk reduction and an evaluation of the efficacy of interventions. In: JordanJ, BardéB, ZeiherA editor(s). Contributions toward evidence-based psychocardiology : a systematic review of the literature. Washington DC; London: American Psychological Association, 2007:83-105. 
Begg 1996

Begg C, Cho M, Eastwood S, Horton R, Moher D, Olkin I, et al. Improving the quality of reporting of randomized controlled trials. The CONSORT statement. JAMA 1996;276(8):637-9.

\section{Cook 1986}

Cook DG, Shaper AG, Pocock SJ, Kussick SJ. Giving up smoking and the risk of heart attacks. A report from The British Regional Study. Lancet 1986;2(8520):1376-80.

\section{Critchley 2003}

Critchley JA, Capewell S. Mortality risk reduction associated with coronary heart disease: a systematic review. JAMA 2003;290:86-97.

\section{Cullen 1997}

Cullen P, Schulte H, Assmann G. The Münster Heart Study (PROCAM): total mortality in middle-aged men is increased at low total and LDL cholesterol concentrations in smokers but not in nonsmokers. Circulation 1997;96(7):2128-36.

\section{DeBacker 2003}

De Backer G, Ambrosioni E, Borch-Johnson K, Brotons C, Cifkova $\mathrm{R}$, Dallongeville J, et al. European guidelines on cardiovascular disease prevention in clinical practice. European Heart Journal 2003;24: 1601-10.

\section{Deeks 1999}

Deeks J, on Behalf of the Statistical Methods Working Group of the Cochrane Collaboration. Statistical methods programmed in meta view.

Version

4. Available at: http://www.cochrane.org/docs/statisticalmethods.pdf [accessed 01/01/2007] 1999.

Fulton 1997

Fulton JE, Shekelle RB. Cigarette smoking, weight gain, and coronary mortality: results from the Chicago Western Electric Study. Circulation 1997;96(5):1438-44.

\section{Higgins 2003}

Higgins JPT, Thompson SG, Deeks JJ, Altman DG. Measuring inconsistency in meta-analyses. BMJ 2003;327:557-60.

\section{Jacobs 1999}

Jacobs DR, Adachi H, Mulder I, Kromhout D, Menotti A, Nissinen A, et al. Cigarette smoking and mortality risk. Twenty-five-year follow-up of the Seven Country Study. Archives of Family Medicine 1999; 159:733-40.

\section{Jüni 2001}

Jüni P, Altman G, Egger M. Assessing the quality of controlled clinical trials. BMJ 2001;323(7303):42-6.

\section{Kawachi 1993}

Kawachi I, Colditz GA, Stampfer MJ, Willett WC, Manson JE, Rosner B, et al. Smoking cessation in relation to total mortality rates in women. A prospective cohort study. Annals of Internal Medicine 1993;119(10):992-1000.

\section{Kawachi 1994}

Kawachi I, Colditz GA, Stampfer MJ, Willett WC, Manson JE, Rosner B, et al. Smoking cessation and time course of desreased risk of coronary heart disease in middle-aged women. Archives of Internal Medicine 1994;154(2):169-75.

\section{Keil 1998}

Keil U, Liese AD, Hense HW, Filipiak B, Döring A, Stieber J, et al. Classical risk factors and their impact on incident non-fatal and fatal myocardial infarction and all-cause mortality in southern Germany. European Heart Journal 1998;19:1197-207.

\section{Lancaster 2004}

Silagy C, Stead L. Physician advice for smoking cessation. Cochrane Database of Systematic Reviews 2004, Issue 4. Art. No.: CD000165. DOI:10.1002/14651858.CD000165.pub2.

\section{Lancaster 2005a}

Lancaster T, Stead L. Individual behavioural counselling for smoking cessation. Cochrane Database of Systematic Reviews 2005, Issue 2. Art. No.: CD001292. DOI:10.1002/14651858.CD001292.pub2.

\section{Lancaster 2005b}

Lancaster T, Stead L. Self-help interventions for smoking cessation. Cochrane Database of Systematic Reviews 2005, Issue 3. Art. No. CD001118. DOI:10.1002/14651858.CD001118.pub2.

\section{Luoto 1998}

Luoto R, Prättäla R, Uutela A, Puska P. Impact of unhealthy behaviors on cardiovascular mortality in Finland, 1978-1993. Preventive Medicine 1998;27:93-100.

\section{Njolstad 1996}

Njolstad I, Arnesen E, Lund-Larsen PG. Smoking, serum lipids, blood pressure, and sex differences in myocardial infarction. A 12 year follow-up of the Finnmark Study. Circulation 1996;93(3):450 6

\section{Nyboe 1991}

Nyboe J, Jensen G, Appleyard M, Schnohr P. Smoking and the risk of first acute myocardial infarction. American Heart Journal 1991; 122(2):438-47.

\section{Ockene 1997}

Ockene IS, Miller NH. Cigarette smoking, cardiovascular disease, and stroke: a statement for healthcare professionals from the American Heart Association. Circulation 1997;96(9):3243-7.

\section{Patrick 1994}

Patrick DL, Cheadle A, Thompson DC, Diehr P, Koepsel T, Kinne $S$. The validity of self-reported smoking: a review and meta-analysis. American Journal of Public Health 1994;84:1086-93.

\section{Prescott 1998}

Prescott E, Hippe M, Schnohr P, Hein HO, Vestbo J. Smoking and risk of myocardial infarction in women and men: longitudinal population study. BMJ 1998;316:1043-7.

\section{Prochaska 1986}

Prochaska JO, DiClemente CC. The transtheoretical approach. In NorcrossJC editor(s). Casebook of eclectic psychotherapy. New York: Brunner \& Mazel, 1987:Brunner \& Mazel.

\section{Rice 2004}

Rice VH, Stead L. Nursing interventions for smoking cessation. Cochrane Database of Systematic Reviews 2004, Issue 1. Art. No.: CD001188. DOI:10.1002/14651858.CD001188.pub3.

\section{Riemsma 2003}

Riemsma RP, Pattenden J, Bridle C, Sowden A, Mather L, Watt IS, et al. Systematic review of the effectiveness of stage based interventions to promote smoking cessation. BMJ 2003;326(7400):1175-7.

\section{Rigotti 2007}

Rigotti NA, Munafo MR, Murphy MFG, Stead L. Interventions for smoking cessation in hospitalised patients. Cochrane Database 
of Systematic Reviews 2007, Issue 3. Art. No.: CD001837. DOI: 10.1002/14651858.CD001837.pub2.

\section{Rollnick 1997}

Rollnick S, Butler CC, Stott N. Helping smokers make decisions: the enhancement of brief intervention for general medical practice. Patient Education and Counseling 1997;31(3):191-203.

\section{Shaper 1985}

Shaper AG, Pocock SJ, Walker M, Philips AN, Whitehead TP, MacFarlane PW. Risk factors for ischemic heart disease: the prospective phase of British Regional Heart Study. Journal of Epidemiology and Community Health 1985;39(3):197-209.

\section{Stead 2005}

Stead

L, Lancaster T. Group behaviour therapy programmes for smoking cessation. Cochrane Database of Systematic Reviews 2005, Issue 2. Art. No.: CD001007. DOI:10.1002/14651858.CD001007.pub2.

\section{Stead 2006}

Stead L, Lancaster T, Perera R. Telephone counselling for smoking cessation. Cochrane Database of Systematic Reviews 2006, Issue 3. Art. No.: CD002850. DOI:10.1002/14651858.CD002850.pub2.

\section{Tunstall-Pedoe 1997}

Tunstall-Pedoe H, Woodward M, Tavendale R, A' Brook R, McCluskey MK. Comparison of the prediction by 27 different factors of coronary heart disease and death in men and women of the Scottish Heart Health Study: cohort study. BMJ 1997;315(7110):722-9.

\section{Tverdal 1993}

Tverdal A, Thelle D, Stensvold I, Leren P, Bjartveit K. Mortality in relation to smoking history: 13 years follow-up of 68,000 Norwegian men and women 35-49 years. Journal of Clinical Epidemiology 1993; 46(5):475-87. van der Meer 2001

van der Meer RM, Wagena EJ, Ostelo RWJG, Jacobs JE, von Schayck CP. Smoking cessation for chronic obstructive pulmonary disease. Cochrane Database of Systematic Reviews 2001, Issue 1. Art. No.: CD002999. DOI:10.1002/14651858.CD002999.

\section{vanSluis 2004}

van Sluijs EM, van Poppel MN, van Mechelen W. Stage-based lifestyle interventions in primary care. Are they effective?. American Journal of Preventive Medicine 2004;26(4):330-43.

\section{Wiggers 2003}

Wiggers LC, Smets EM, de Haes JC, Peters RJ, Legemate DA. Smoking cessation interventions in cardiovascular patients. European Journal of Vascular \& Endovascular Surgery 2003;26:467-75.

\section{Willett 1987}

Willett WC, Green A, Stampfer MJ, Speizer FE, Colditz GA, Rosner $\mathrm{B}$, et al. Relative and absolute excess risks of coronary heart disease among women who smoke cigarettes. New England Journal of Medicine 1987;317(21):1303-9.

\section{Woodward 1992}

Woodward M, Tunstall-Pedoe H. Biochemical evidence of persistent heavy smoking after a coronary diagnosis despite self-reported reduction: analysis from the Scottish Heart Health Study. European Heart Journal 1992;13(2):160-5.

\section{Woodward 1999}

Woodward M, Moohan M, Tunstall-Pedoe H. Self-reported smoking, cigarette yields and inhalation biochemistry related to the incidence of coronary heart disease: results from the Scottish Heart Health Study. Journal of Epidemiology \& Biostatistics 1999;4(4):28595 .

* Indicates the major publication for the study

TAB LES

\section{Characteristics of included studies}

\begin{tabular}{ll} 
Study & Allen $\mathbf{1 9 9 6}$ \\
\hline Methods & OM \\
\hline Participants & 138 women who underwent first-time CABG at a hospital. \\
& IG: 14 smokers \\
& CG: 11 smokers \\
\hline Interventions & Usual care: patient education and instructions for exercise. \\
& Psychosocial intervention: nurse-directed multimodal behavioural program based on social cognitive theory \\
& (videotape, workbook, counselling). Started with discharge from hospital, two updates 1 and 2 months later \\
& (BT, Ph, SH, MR, Intensity 4) \\
\hline Outcomes & Follow-up at 12 months (abstinence self report) \\
\hline Notes & IG: OM = 64.3\% \\
& CG: OM = 54.5\% \\
\hline Allocation concealment & A - Adequate \\
\hline Psychosocial interventions for smoking cessation in patients with coronary heart disease (Review) \\
Copyright $\odot$ 2008 The Cochrane Collaboration. Published by John Wiley \& Sons, Ltd
\end{tabular}




\section{Characteristics of included studies (Continued)}

\begin{tabular}{|c|c|}
\hline Study & Burt 1974 \\
\hline Methods & $\mathrm{OM}$ \\
\hline Participants & $\begin{array}{l}280 \text { men in a coronary care unit with AMI } \\
\text { IG: } 125 \text { smokers } \\
\text { CG: } 98 \text { smokers }\end{array}$ \\
\hline Interventions & $\begin{array}{l}\text { Usual care: conventional advice to stop smoking by physician. } \\
\text { Psychosocial intervention: information about the effects of smoking by physician and nurse, reinforced by a } \\
\text { booklet about coronary-risk factors. Continued in follow-up clinic and through a community nurse. } \\
\text { (Specific, Intensity 5) }\end{array}$ \\
\hline Outcomes & Follow-up at 12 months (abstinence self-report) \\
\hline Notes & $\begin{array}{l}\text { IG: } \mathrm{OM}=63.2 \% \\
\mathrm{CG}: \mathrm{OM}=27.5 \%\end{array}$ \\
\hline Allocation concealment & $\mathrm{C}$ - Inadequate \\
\hline Study & CASIS 1992 \\
\hline Methods & OM, ITT \\
\hline Participants & $\begin{array}{l}267 \text { smokers with CAD of } 3 \text { hospitals who scheduled for coronary arteriography } \\
\text { IG: } 135 \text { smokers } \\
\text { CG: } 132 \text { smokers }\end{array}$ \\
\hline Interventions & $\begin{array}{l}\text { Usual care: brief advice from physician to stop smoking. } \\
\text { Psychosocial intervention: intervention provided by trained behaviourally oriented health educators: inpatient } \\
\text { counselling session ( } 30 \mathrm{~min} \text { ), outpatient counselling visits and telephone calls (at } 1 \text { and } 3 \text { weeks, abstinent } \\
\text { smokers at } 3 \text { months, relapsed smokers at } 2 \text { and } 4 \text { months), outpatient group program, self-help materials. } \\
\text { (BT, Ph, SH, Specific, Intensity 4) }\end{array}$ \\
\hline Outcomes & Follow-up at 6,12 and 60 months (validation by saliva samples) \\
\hline Notes & $\begin{array}{l}\text { IG: } \mathrm{OM}=57.3 \% \\
\text { ITT }=34.8 \% \\
\text { CG: } \mathrm{OM}=47.4 \% \\
\text { ITT }=28 \%\end{array}$ \\
\hline Allocation concealment & B - Unclear \\
\hline
\end{tabular}

\begin{tabular}{ll} 
Study & Carlsson $\mathbf{1 9 9 7}$ \\
\hline Methods & OM \\
\hline Participants & 168 patients with AMI admitted to the coronary care unit at Malmö General Hospital \\
& IG: 32 smokers \\
CG: 35 smokers
\end{tabular}

Interventions Usual care: two visits to general practitioner.

Psychosocial intervention: nurse-directed secondary prevention unit after the usual follow-up schedule: education and counselling (individual and group sessions) about smoking, exercise, nutrition for about 9 hours and exercise training 2-3 times per week. Visits to cardiologist after 2, 3, 6 months and to nurse after 3, 5, 6, 9, 12 months.

(MR, Intensity 5)

\begin{tabular}{ll}
\hline Outcomes & Follow-up at 12 months (abstinence self-report) \\
\hline Notes & IG: $\mathrm{OM}=50 \%$ \\
& $\mathrm{CG}: \mathrm{OM}=25.7 \%$ \\
\hline Allocation concealment & $\mathrm{B}-$ Unclear \\
\hline Psychosocial interventions for smoking cessation in patients with coronary heart disease (Review)
\end{tabular}

Copyright (c) 2008 The Cochrane Collaboration. Published by John Wiley \& Sons, Ltd 


\section{Characteristics of included studies (Continued)}

Study

DeBusk 1994

Methods

$\mathrm{OM}$

Participants

585 patients with AMI in five medical centres

IG: 131 smokers

CG: 120 smokers

Interventions Usual care: counselling on dietary change, lipid lowering therapy, and on demand smoking cessation interventions.

Psychosocial intervention: physician-directed, nurse-managed, home-based case-management system (behavioural intervention, telephone and mail contact) in addition to the usual care. Started in the hospital and finished 12 months later.

(BT, Ph, SH, MR, Intensity 5)

\begin{tabular}{ll}
\hline Outcomes & Follow-up at 6 and 12 months (abstinence validated) \\
\hline Notes & IG: OM $=70.2 \%$ \\
& CG: OM $=53.3 \%$ \\
\hline Allocation concealment & B - Unclear \\
\hline
\end{tabular}

\begin{tabular}{|c|c|}
\hline Study & Dornelas 2000 \\
\hline Methods & OM, ITT \\
\hline Participants & $\begin{array}{l}100 \text { smokers with AMI admitted to hospital } \\
\text { IG: } 54 \text { smokers } \\
\text { CG: } 46 \text { smokers }\end{array}$ \\
\hline Interventions & $\begin{array}{l}\text { Usual care: verbal and written recommendation to watch education video of AHA. } \\
\text { Psychosocial intervention: bedside cessation counselling (motivation for cessation, relapse prevention) deliv- } \\
\text { ered by a psychologist based on the transtheoretical model. } \\
\text { Seven telephone calls at } 1,4,8,12,16,20,26 \text { weeks } \\
\text { (BT, Ph, Specific, Intensity } 4 \text { ) }\end{array}$ \\
\hline Outcomes & Follow-up at 6 and 12 months (validation by a significant other) \\
\hline Notes & $\begin{array}{l}\text { IG: OM }=70 \% \\
\text { ITT }=51.8 \% \\
\text { CG: OM }=40 \% \\
\text { ITT }=34.8 \%\end{array}$ \\
\hline Allocation concealment & A - Adequate \\
\hline
\end{tabular}

Study

Hajek 2002

Methods

OM, ITT

Participants

540 patients in hospitals in UK with MI and CABG

IG: 274

CG: 266

Interventions $\quad$ Usual care: verbal advice to stop smoking and booklet "Smoking and your heart". Psychosocial intervention: in 17 hospitals patients motivated to stop smoking received intervention. Education with booklet (Smoking and your Heart) from the British Heart Foundation. Short quiz on contents of the booklet; support of other cardiac patient is arranged by nurse Duration about $34 \mathrm{~min}$ (SH, Specific, Intensity 1)

\begin{tabular}{ll}
\hline Outcomes & Follow-up at 6 weeks and 12 months (validated) \\
\hline Notes & IG: OM $=39 \%$ \\
& ITT $=36 \%$ \\
CG: OM $=43 \%$ \\
ITT $=41 \%$ \\
\hline
\end{tabular}

Psychosocial interventions for smoking cessation in patients with coronary heart disease (Review)

Copyright $(2008$ The Cochrane Collaboration. Published by John Wiley \& Sons, Ltd 


\section{Characteristics of included studies (Continued)}

Allocation concealment A-Adequate

Study

Methods

Participants

Interventions
Heller 1993

$\mathrm{OM}$

450 patients with AMI discharged from the hospital

IG: 66 smokers

CG: 73 smokers

Psychosocial intervention: letter to the subjects' GP, three mail-out packages for the subjects (information about nutrition, smoking, walking programme) and monthly newsletters.

(SH, MR, Intensity 1)

Outcomes $\quad$ Follow-up at 6 months (abstinence self-report)

Notes $\quad$ IG: $\mathrm{OM}=65 \%$

$\mathrm{CG}: \mathrm{OM}=53 \%$

Allocation concealment $\mathrm{C}$ - Inadequate

\begin{tabular}{ll} 
Study & Ortigosa 2000 \\
\hline Methods & OM, ITT \\
\hline Participants & 90 patients with myocardial infarction in hospital in Spain \\
& IG: 43 smokers \\
& CG: 47 smokers \\
\hline Interventions & Usual care: advice only. \\
& Psychosocial intervention: advice by doctor immediately after admission to hospital (10 minutes). Additional \\
& enhancement of motivation by nurses and phone contacts (after 2, 3, 4 weeks). \\
& (Ph, Specific, Intensity 3) \\
\hline Outcomes & Follow-up at 1,3 and 12 months (validated) \\
\hline Notes & IG: OM $=62 \%$ \\
& ITT $=61 \%$ \\
CG: OM $=69 \%$ \\
ITT $=66 \%$
\end{tabular}

\section{Study}

Methods

Participants

\section{Quist-Paulsen 2003}

OM, ITT

Patients in hospital (reasons myocardial infarction, angina pectoris, coronary artery bypass surgery)

IG: 118 smokers

CG: 122 smokers

Interventions Usual care: no specific intervention.

Psychosocial intervention: group intervention with nurses (twice a week). Booklet with emphasis on health benefits from smoking cessation. Also fear arousing message about death rates of persistent smokers. Advice not to smoke during hospital stay and motivation for NRT if needed additional phone contacts (5 times) in 5 months after hospital stay.

(BT, Ph, SH, Specific, Intensity 4)

\begin{tabular}{ll}
\hline Outcomes & Follow-up 12 months (validated) \\
\hline Notes & IG: OM $=57 \%$ \\
& ITT $=48 \%$ \\
& CG: $\mathrm{OM}=37 \%$
\end{tabular}

Psychosocial interventions for smoking cessation in patients with coronary heart disease (Review)

Copyright (c) 2008 The Cochrane Collaboration. Published by John Wiley \& Sons, Ltd 


\section{Characteristics of included studies (Continued)}

\begin{tabular}{|c|c|}
\hline & ITT $=36 \%$ \\
\hline Allocation concealment & B - Unclear \\
\hline Study & Reid 2003 \\
\hline Methods & ITT \\
\hline Participants & $\begin{array}{l}\text { Patients in hospital in Canada (reasons: angiography, PTCA, Myocardial infarction, coronary artery bypass } \\
\text { surgery. } \\
\text { IG: } 126 \text { smokers } \\
\text { CG: } 128 \text { smokers }\end{array}$ \\
\hline Interventions & $\begin{array}{l}\text { Usual care: no additional intervention after discharge. } \\
\text { Psychosocial intervention: assessment of smoking status after } 4 \text { weeks. Abstinent patients were reinforced. } \\
\text { Those still smoking were offered support by nurse ( } 3 \text { sessions with } 20 \text { minutes in } 8 \text { weeks) and additionally } \\
\text { nicotine patch therapy } \\
\text { (BT, Ph, SH, Specific, Intensity } 4)\end{array}$ \\
\hline Outcomes & Follow-up at 3 and 12 months (not validated self-report) \\
\hline Notes & $\begin{array}{l}\text { IG: } \mathrm{ITT}=39 \% \\
\text { CG: } \mathrm{ITT}=36 \%\end{array}$ \\
\hline Allocation concealment & A - Adequate \\
\hline
\end{tabular}

\begin{tabular}{ll} 
Study & Rigotti $\mathbf{1 9 9 4}$ \\
\hline Methods & ITT \\
\hline Participants & 93 patients (smokers) scheduled for CABS in the postoperative cardiac surgery unit at Massachusetts General \\
& Hospital \\
& IG: 44 smokers \\
& CG: 43 smokers \\
\hline Interventions & Usual care: Brief advice not to smoke within a group session. \\
& Psychosocial intervention: \\
& Nurse-based smoking cessation and relapse prevention programme adapted from the American Lung As- \\
& sociation's "In Control" programme: three-counselling sessions, videotape, family members were included. \\
& Phone call 1 week after discharge by nurse. \\
& (BT, Ph, SH, Specific, Intensity 3) \\
\hline Outcomes & Follow-up at 2, 4, 8, 12 months and 5 years (validation by saliva cotinine) \\
\hline Notes & IG: ITT = 43\% \\
CG: ITT = 44\%
\end{tabular}

\begin{tabular}{ll} 
Study & Sivarajan $\mathbf{1 9 8 3}$ \\
\hline Methods & OM, ITT \\
\hline Participants & 258 patients hospitalised with AMI \\
& IG1: 43 smokers \\
& IG2: 39 smokers \\
& CG: 37 smokers \\
\hline Interventions & Usual care: conventional medical and nursing management. \\
& Psychosocial intervention: two intervention groups - EG1: exercise only (for 12 weeks, weekly clinic visits); \\
& EG2: exercise, teaching and counselling ( 8 group sessions about risk factors, diet, exercise, stress management \\
& etc, individual counselling if needed). Data only of EG 2 used for analysis. \\
& (BT, SH, MR, Intensity 4) \\
\hline
\end{tabular}




\section{Characteristics of included studies (Continued)}

\begin{tabular}{ll}
\hline Notes & IG: OM $=48 \%$ \\
& ITT $=33 \%$ \\
& CG: OM $=58 \%$ \\
& ITT $=37 \%$ \\
\hline Allocation concealment & B - Unclear \\
\hline Study & Taylor $\mathbf{1 9 9 0}$ \\
\hline Methods & OM \\
\hline Participants & 173 patients (smokers) admitted to hospital with AMI \\
& IG: 72 smokers \\
& CG: 58 smokers \\
\hline Interventions & Usual care: no specific instruction to stop smoking. 10\% participated in non smoking classes. \\
& Psychosocial intervention: nurse-managed intervention based on social learning theory: manual "Staying \\
& Free", 2 audio tapes for relaxation. Telephone contact after discharge (6 times), counselling after relapse. \\
& (BT, Ph, SH, Specific, Intensity 4) \\
\hline Outcomes & Follow-up at 6 and 12 months (biochemical validation) \\
\hline Notes & IG: OM = 70\% \\
& CG: OM = 44\% \\
\hline Allocation concealment & A - Adequate
\end{tabular}

Study van Elderen (group)

Methods

Participants

Diagnosis: MI (144)
IG: 64 smokers
CG: 64 smokers

Interventions

$\mathrm{OM}$

CG: 64 smokers

Of 477 patients with CHD after discharge from hospital 258 were included.

Usual care: standard rehabilitation with medical care and physical training.

Psychosocial intervention: health education programme "Heart and Health" based on Ellis' Rational Emotive Therapy (ABCDE model): information about heart disease, risks, diet, exercise, identification and modification of irrational beliefs.

8 weekly group sessions ( $2 \mathrm{~h}$ ) for the patients and their partners, one follow-up session at 2 months.

(BT, MR, Intensity 4)

Outcomes Follow-up at 3 and 12 months (abstinence self-report)

Notes IG: $\mathrm{OM}=62 \%$

CG: $\mathrm{OM}=50 \%$

Allocation concealment $\mathrm{B}-$ Unclear

Study $\quad$ van Elderen (phone)

\begin{tabular}{ll}
\hline Methods & OM \\
\hline Participants & 60 patients admitted to hospital with AMI \\
& IG: 15 smokers \\
& CG: 16 smokers \\
\hline Interventions & Usual care: standard medical care. \\
& Psychosocial intervention: health education and counselling programme: two nurse-based counselling ses- \\
& sions, two group health education sessions (medication, aetiology of MI, risk factors, anxiety, depression etc). \\
& Weekly telephone contacts by nurse after discharge for 6 weeks. \\
\hline
\end{tabular}

Psychosocial interventions for smoking cessation in patients with coronary heart disease (Review)

Copyright $(2008$ The Cochrane Collaboration. Published by John Wiley \& Sons, Ltd 
(Ph, SH, MR, Intensity 4)

\begin{tabular}{|c|c|}
\hline Outcomes & Follow-up after intervention, at 8 weeks and 1 year (abstinence self-report) \\
\hline Notes & $\begin{array}{l}\text { IG: } O M=60 \% \\
\text { CG: } O M=37 \%\end{array}$ \\
\hline Allocation concealment & B - Unclear \\
\hline $\begin{array}{l}\mathrm{OM}=\text { optimistic model; } \mathrm{IT}^{2} \\
\text { infarction; } \mathrm{CG}=\text { control }\end{array}$ & $\begin{array}{l}=\text { intent to treat analysis; } \mathrm{CABG}=\text { coronary artery bypass surgery } \mathrm{CAD}=\text { coronary artery disease; } \mathrm{AMI}=\text { acute myocardial } \\
\text { group; } \mathrm{IG}=\text { experimental intervention group; } \mathrm{GP}=\text { general practitioner }\end{array}$ \\
\hline $\begin{array}{l}\text { Duration of treatment is coc } \\
\text { coding 1: single initial conta } \\
\text { coding 2: one or more conta } \\
\text { coding 3: any initial contact } \\
\text { coding 4: any initial contact } \\
\text { coding 5: any initial contact } \\
\text { Number in notes section sh }\end{array}$ & $\begin{array}{l}\text { ed as follows (intensity): } \\
\text { ct lasting }<=1 \text { hour, no follow-up support } \\
\text { ts in total }>1 \text { hour, no follow-up support } \\
\text { plus follow-up }<=1 \text { month } \\
\text { plus follow-up }>1 \text { month and }<=6 \text { month } \\
\text { plus follow-up }>6 \text { month. } \\
\text { w abstince rates in percent }\end{array}$ \\
\hline
\end{tabular}

\section{Characteristics of excluded studies}

\begin{tabular}{|c|c|}
\hline Study & Reason for exclusion \\
\hline Andersen 2002 & Patients with other disease, or healthy subjects \\
\hline Baughman 1982 & No intervention specified or no specific smoking cessation intervention \\
\hline Belson 2002 & Heterogeneity in diagnosis included / no assessment of smoking status \\
\hline Bolman 2002 & Follow up too short \\
\hline Brenner 1989 & No intervention specified or no specific smoking cessation intervention / no assessment of smoking status \\
\hline Byfield 2001 & Patients with other disease, or healthy subjects / no assessment of smoking status \\
\hline Campbell 1996 & Heterogeneity in diagnosis included \\
\hline Campbell 1998a & No clear diagnosis of CHD \\
\hline Campbell 1998b & No clear diagnosis of CHD \\
\hline Circo 1985 & Follow up too short \\
\hline Connett 1984 & No information about diagnosis included \\
\hline Cook 1989 & No data reported \\
\hline Cupples 1999 & Patients with other heart disease \\
\hline Eaker 1982 & Patients with other disease, or healthy subjects \\
\hline Engblom 1992 & no intervention specified or no specific smoking cessation intervention \\
\hline Erdman 1983 & No intervention specified or no specific smoking cessation intervention \\
\hline Feeney 2001 & Drop out $>50 \%$ \\
\hline Finnegan 1985 & $\begin{array}{l}\text { Cross sectional analysis, not sufficient data / no intervention specified or no specific smoking cessation inter- } \\
\text { vention }\end{array}$ \\
\hline Fletcher 1987 & $\begin{array}{l}\text { No intervention specified or no specific smoking cessation intervention / no comparison of smoking status } \\
\text { feasible }\end{array}$ \\
\hline Fortmann 1994 & $\begin{array}{l}\text { No intervention specified or no specific smoking cessation intervention / no comparison of usual care and } \\
\text { specific psychosocial intervention }\end{array}$ \\
\hline Frasure-Smith 1997 & No comparison of smoking status feasible \\
\hline Fredrickson 1995 & $\begin{array}{l}\text { Patients with other disease, or healthy subjects / no intervention specified or no specific smoking cessation } \\
\text { intervention / follow up too short }\end{array}$ \\
\hline
\end{tabular}


Hall 1983

Haskell 1994

Hjermann 1986

Horlick 1984

Houston-Miller 1997

Jones 1996

Joseph 1996

Kallio 1981

Knutsen 1991

Kornitzer 1980

Kornitzer 1989

Kristeller 1993

Kuller 1991

Lancaster 1999

Lisspers 1999

Marra 1985

Mayou 2002

McHugh 2001

Meland 1999

Mitsibounas 1992

Murchie 2003

Nisbeth 2000

Ornish 1990

Patel 1985

Prieme 1998

Rice 1994

Risser 1990

Rose 1978

Rose 1982

Rose 1992

Sanders 1989

Schmitz 1999

Simon 2003

Sippel 1999

Steptoe 1999

Steptoe 2001

Stewart 1999

Suurkula 1996

Taylor 1988
Heterogeneity in diagnosis included

No possibility to include data in meta-analysis

Heterogeneity in diagnosis included

No comparison of smoking status feasible

Heterogeneity in diagnosis included

No intervention specified or no specific smoking cessation intervention / no assessment of smoking status

No intervention specified or no specific smoking cessation intervention

Follow up too short

Patients with other disease, or healthy subjects

Patients with other disease, or healthy subjects

Patients with other disease, or healthy subjects / no comparison of smoking status feasible

No comparison of smoking status feasible

Heterogeneity in diagnosis included / no intervention specified or no specific smoking cessation intervention Patients with other disease, or healthy subjects

Assessment of smoking status was made after cardiac procedure had been performed

No intervention specified or no specific smoking cessation intervention

No intervention specified or no specific smoking cessation intervention / no comparison of smoking status feasible

No assessment of smoking status

Cross sectional analysis, not sufficient data

Statistically significant difference in patient characteristics at baseline between intervention and control groups No clear diagnosis of CHD

Patients with other disease, or healthy subjects

No comparison of smoking status feasible / no assessment of smoking status

No information about diagnosis included / no comparison of smoking status feasible

Patients with other disease, or healthy subjects / cross sectional analysis, not sufficient data /no intervention specified or no specific smoking cessation intervention / no assessment of smoking status

Heterogeneity in diagnosis included

Patients with other disease, or healthy subjects

Patients with other disease, or healthy subjects

Patients with other disease, or healthy subjects

Patients with other disease, or healthy subjects

No information about diagnosis included

No comparison of usual care and specific psychosocial intervention

Heterogeneity in diagnosis included

Heterogeneity in diagnosis included

Other heart diseases / patients with other disease, or healthy subjects

Other heart diseases / patients with other disease, or healthy subjects

Other heart diseases / no intervention specified or no specific smoking cessation intervention

Heterogeneity in diagnosis included

No intervention specified or no specific smoking cessation intervention

Psychosocial interventions for smoking cessation in patients with coronary heart disease (Review)

Copyright $\odot 2008$ The Cochrane Collaboration. Published by John Wiley \& Sons, Ltd 


\section{Characteristics of excluded studies (Continued)}

\begin{tabular}{ll} 
Taylor 1997 & No assessment of smoking status \\
\hline Tiffany 1986 & Patients with other disease, or healthy subjects \\
\hline Tonnesen 1999 & Other heart diseases \\
\hline Tonstad 2003 & Heterogeneity in diagnosis included / no intervention specified or no specific smoking cessation intervention \\
\hline Toobert 1998 & No comparison of smoking status feasible \\
\hline Toobert 2000 & No comparison of smoking status feasible \\
\hline Tzivoni 1998 & $\begin{array}{l}\text { Cross sectional analysis, not sufficient data /no intervention specified or no specific smoking cessation inter- } \\
\text { vention }\end{array}$ \\
\hline Vedin 1976 & No intervention specified or no specific smoking cessation intervention \\
\hline Wallner 1999 & No intervention specified or no specific smoking cessation intervention / no assessment of smoking status \\
\hline Waters 1996 & No intervention specified or no specific smoking cessation intervention \\
\hline Wewers 1994 & Heterogeneity in diagnosis included \\
\hline Whitlock 1997 & Heterogeneity in diagnosis included / no information about diagnosis included \\
\hline
\end{tabular}

ADDITIONAL TABLES

\section{Table 01. EMBASE search strategy}

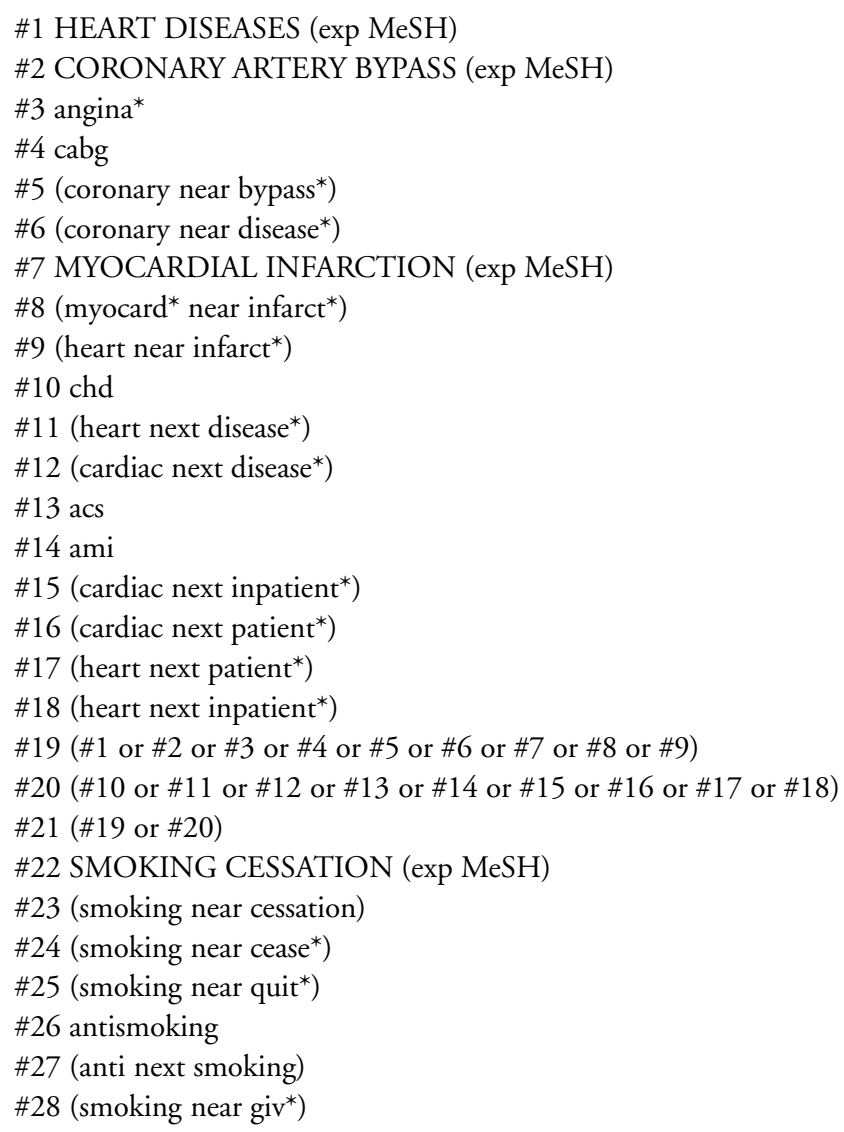


Table 01. EMBASE search strategy (Continued)

\#29 (smoking near stop*)

$\# 30$ (\#22 or \#23 or \#24 or \#25 or \#26 or \#27 or \#28 or \#29)

\#31 (\#21 and \#30)

\section{Table 02. Search strategy for MEDLINE, Pre-MEDLINE, BIOSIS and Journals@Ovid}

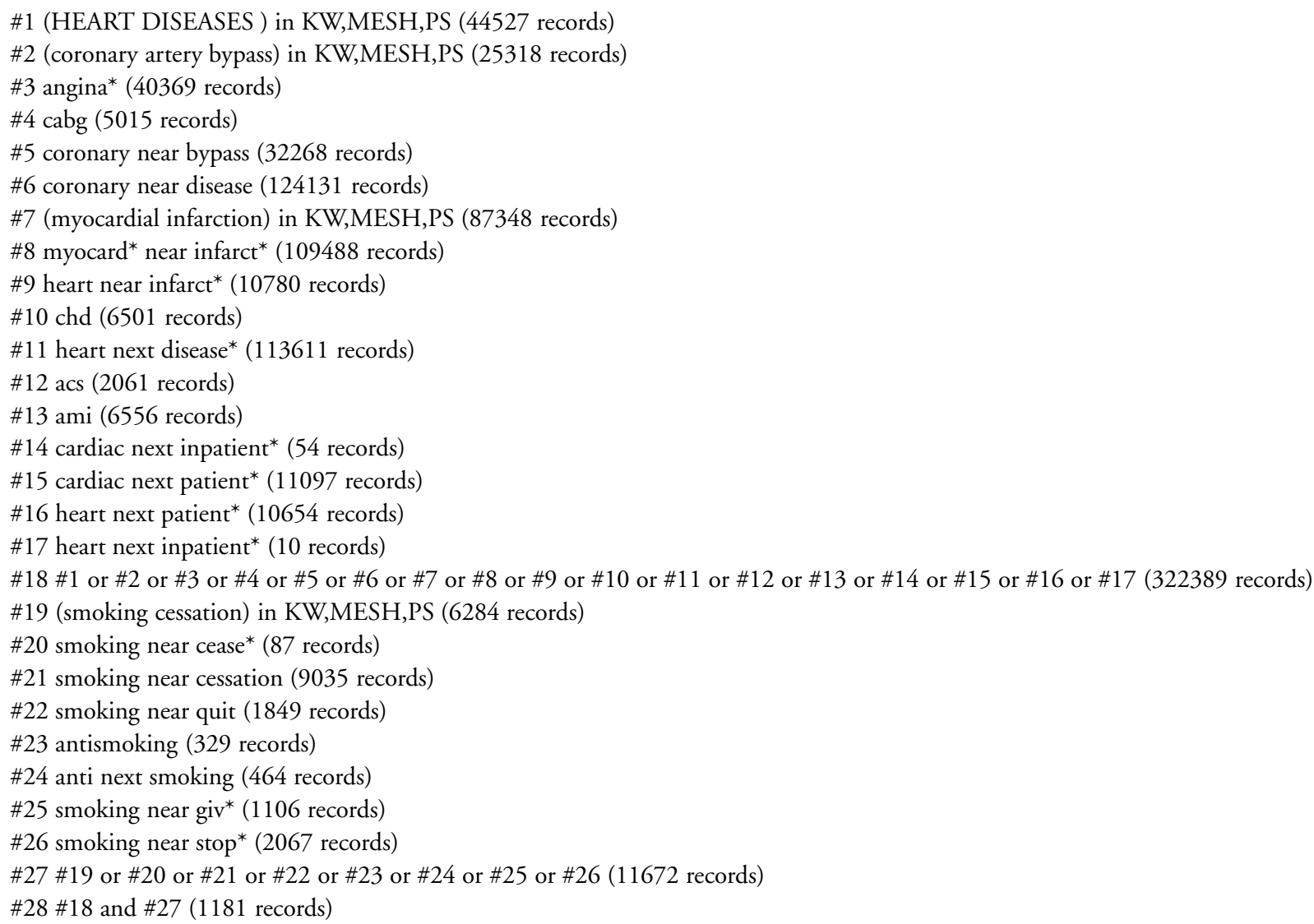

\section{Table 03. Search strategy for PsycINFO}

\#1 TI coronary artery bypass Or AB coronary artery bypass Or MJ coronary artery bypass \#2 TI angina Or AB angina Or MJ angina

\#3 TI cabg Or AB cabg Or MJ cabg

\#4 TI coronary Or AB coronary Or MJ coronary

\#5 TI bypass Or AB bypass Or MJ bypass

\#6 TI myocard Or AB myocard Or MJ myocard

\#7 TI myocard Or AB myocard Or MJ myocard

\#8 TI diseas* Or AB diseas* Or MJ diseas*

\#9 TI heart* Or AB heart* Or MJ heart*

\#10 TI chd Or AB chd Or MJ chd

$\# 11$ TI acs Or AB acs Or MJ acs

Psychosocial interventions for smoking cessation in patients with coronary heart disease (Review)

Copyright $(2008$ The Cochrane Collaboration. Published by John Wiley \& Sons, Ltd 
Table 03. Search strategy for PsycINFO (Continued)

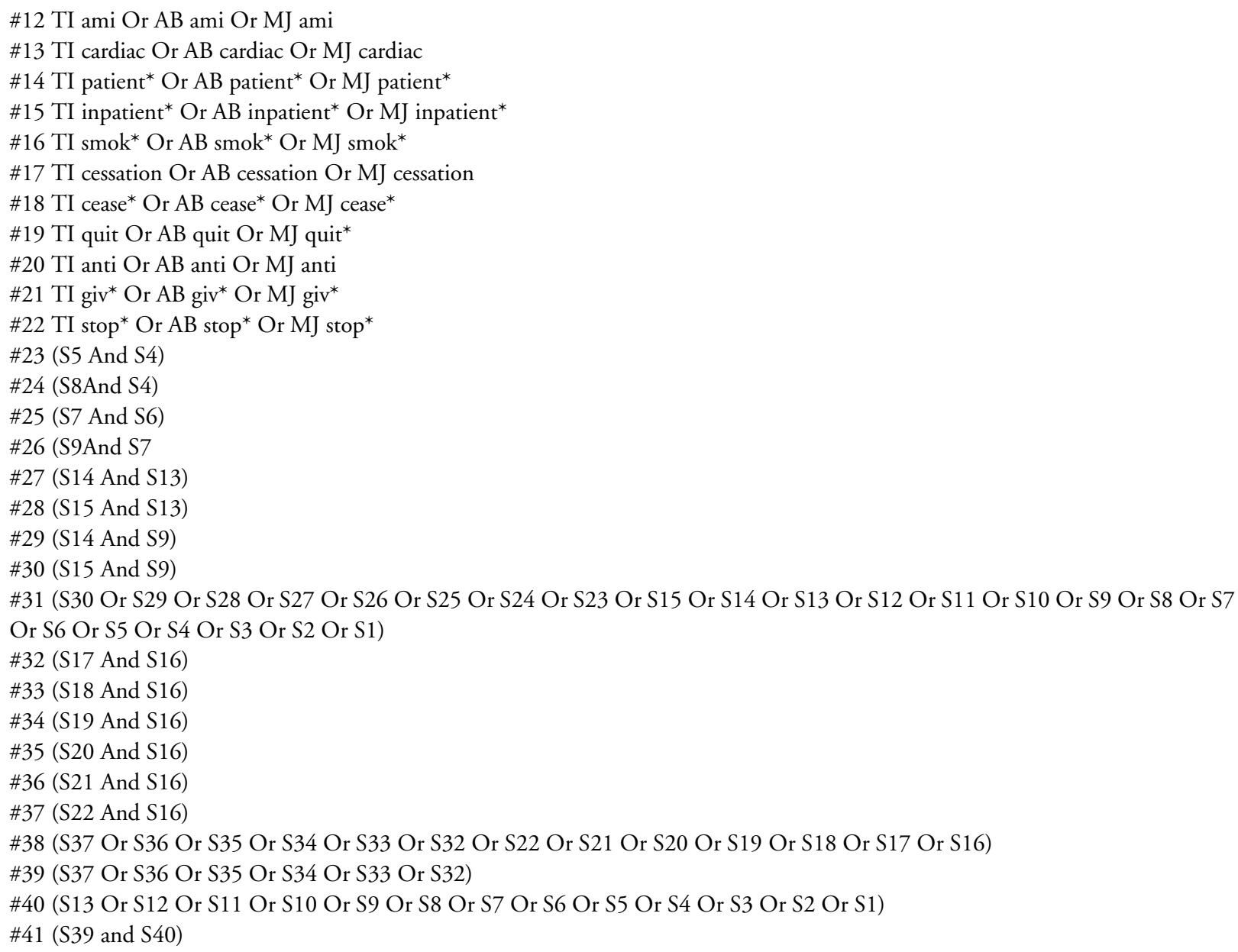

\section{Table 04. Search strategy for PSYNDEXplus}

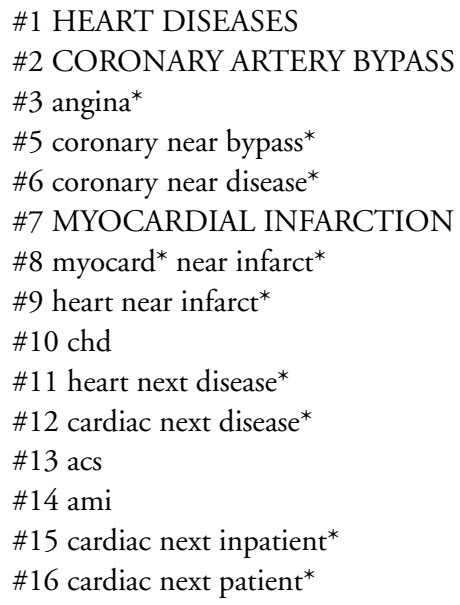

Psychosocial interventions for smoking cessation in patients with coronary heart disease (Review) 
Table 04. Search strategy for PSYNDEXplus (Continued)

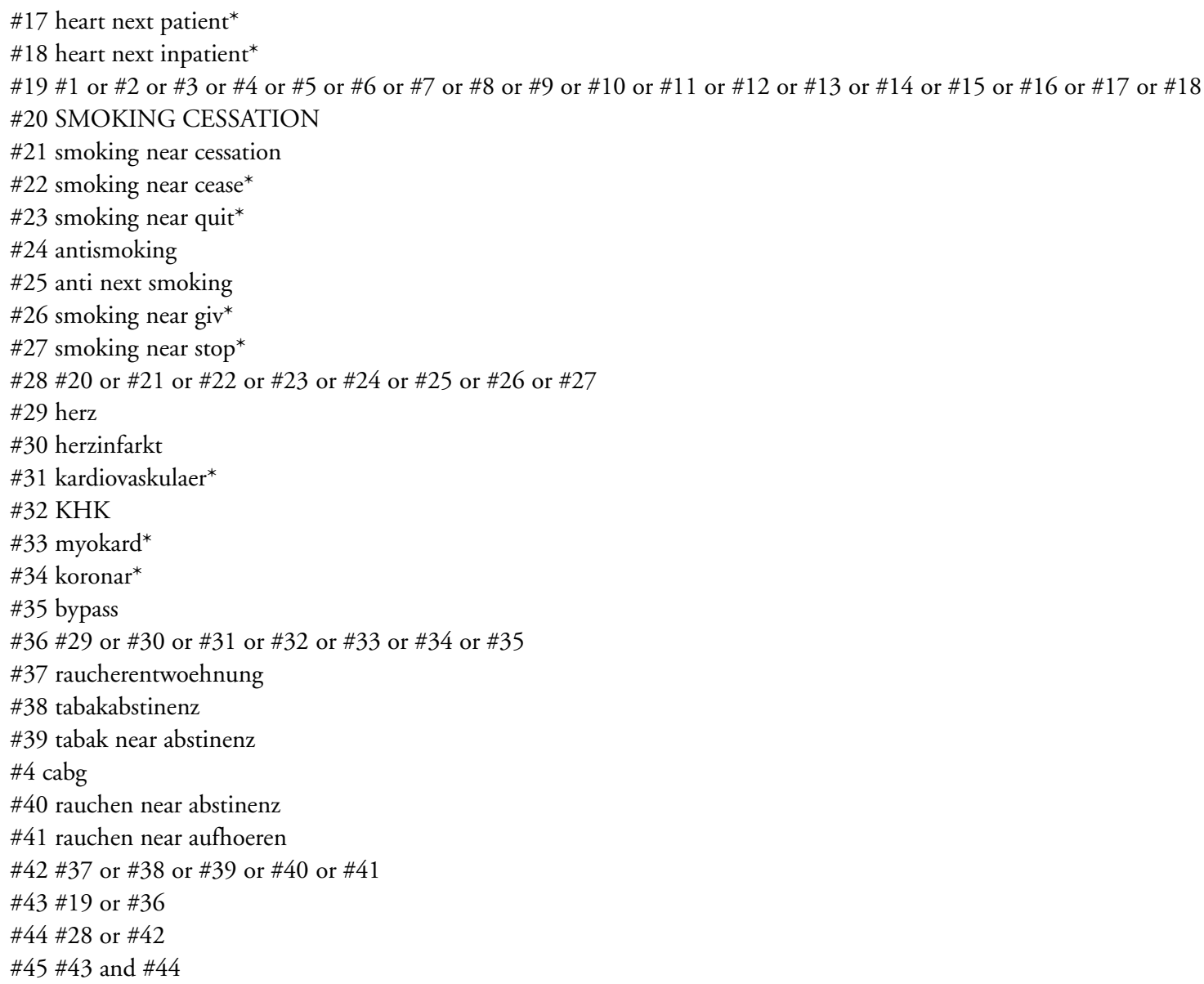

A N A L Y S E S

Comparison 01. Efficacy of psychosocial interventions on abstinence (6 to 12 months; all trials)

Outcome title

No. of

studies

No. of

participants
Statistical method

Effect size
01 Abstinence 6 to 12 months (ITT preferred and OM)

02 Abstinence 6 to 12 months (ITT preferred and OM)

03 Abstinence 6 to 12 months (ITT only)

$\begin{array}{cccc}16 & 2677 & \text { Odds Ratio (Random) 95\% CI } & 1.66[1.25,2.22] \\ 4 & 919 & \text { Odds Ratio (Random) 95\% CI } & 1.10[0.75,1.60] \\ 11 & 2215 & \text { Odds Ratio (Random) 95\% CI } & 1.47[1.10,1.96]\end{array}$

Psychosocial interventions for smoking cessation in patients with coronary heart disease (Review)

Copyright ( 2008 The Cochrane Collaboration. Published by John Wiley \& Sons, Ltd 
Comparison 02. Sensitivity analysis validation (abstinence 6 to 12 months)

\begin{tabular}{lcccc} 
Outcome title & $\begin{array}{c}\text { No. of } \\
\text { studies }\end{array}$ & $\begin{array}{c}\text { No. of } \\
\text { participants }\end{array}$ & Statistical method & Effect size \\
\hline 01 Abstinence at 6 to 12 months & 16 & 2677 & Odds Ratio (Random) 95\% CI & $1.66[1.25,2.22]$ \\
\hline
\end{tabular}

Comparison 03. Grouped by type of intervention (6 to 12 months)

\begin{tabular}{|c|c|c|c|c|}
\hline Outcome title & $\begin{array}{l}\text { No. of } \\
\text { studies }\end{array}$ & $\begin{array}{c}\text { No. of } \\
\text { participants }\end{array}$ & Statistical method & Effect size \\
\hline $\begin{array}{l}01 \text { Abstinence } 6 \text { to } 12 \text { months } \\
\text { BEHAVIORAL THERAPY }\end{array}$ & 16 & 2677 & Odds Ratio (Random) 95\% CI & $1.66[1.25,2.22$ \\
\hline $\begin{array}{l}02 \text { Abstinence } 6 \text { to } 12 \text { months } \\
\text { TELEPHONE SUPPORT }\end{array}$ & 16 & 2677 & Odds Ratio (Random) 95\% CI & $1.66[1.25,2.22$ \\
\hline $\begin{array}{l}03 \text { Abstinence } 6 \text { to } 12 \text { months } \\
\text { SELF HELP MATERIALS }\end{array}$ & 16 & 2677 & Odds Ratio (Random) 95\% CI & $1.66[1.25,2.22$ \\
\hline $\begin{array}{l}04 \text { Abstinence } 6 \text { to } 12 \text { months } \\
\text { Specific vs. Multi-Risk-Factor } \\
\text { Intervention }\end{array}$ & 16 & 2677 & Odds Ratio (Random) 95\% CI & $1.66[1.25,2.22$ \\
\hline
\end{tabular}

Comparison 04. Sensitivity analysis brief / intense intervention (6 to 12 months)

\begin{tabular}{lcccc} 
Outcome title & $\begin{array}{c}\text { No. of } \\
\text { studies }\end{array}$ & $\begin{array}{c}\text { No. of } \\
\text { participants }\end{array}$ & Statistical method & Effect size \\
\hline $\begin{array}{l}\text { 01 Abstinence } 6 \text { to } 12 \text { months all } \\
\text { studies }\end{array}$ & 16 & 2677 & Odds Ratio (Random) 95\% CI & $1.66[1.25,2.22]$ \\
\hline
\end{tabular}

Comparison 05. Efficacy of psychosocial interventions on long term abstinence (five years)

\begin{tabular}{lcccc} 
Outcome title & $\begin{array}{c}\text { No. of } \\
\text { studies }\end{array}$ & $\begin{array}{c}\text { No. of } \\
\text { participants }\end{array}$ & Statistical method & Effect size \\
\hline $\begin{array}{l}01 \text { Abstinence five years (OM } \\
\text { only) }\end{array}$ & 2 & 226 & Odds Ratio (Random) 95\% CI & $1.32[0.78,2.24]$ \\
$\begin{array}{l}02 \text { Abstinence five years (ITT } \\
\text { only) }\end{array}$ & 2 & 348 & Odds Ratio (Random) 95\% CI & $1.23[0.79,1.93]$ \\
\hline
\end{tabular}

\section{COVER SHEET}

Title

\section{Authors}

Contribution of author(s)

Issue protocol first published

Review first published

Date of most recent amendment

Date of most recent SUBSTANTIVE amendment
Psychosocial interventions for smoking cessation in patients with coronary heart disease

Barth J, Critchley J, Bengel J

JBa performed initial searches for studies, assessed studies for inclusion, carried out data extraction and edited review.

JC gave advice on statistical procedures, and edited review

JBe edited review

/

$2008 / 1$

30 October 2007

03 October 2007

Psychosocial interventions for smoking cessation in patients with coronary heart disease (Review) 
What's New

Date new studies sought but none found

Date new studies found but not yet included/excluded

Date new studies found and included/excluded

Date authors' conclusions section amended

Contact address

DOI

Cochrane Library number

Editorial group

Editorial group code
Information not supplied by author

Information not supplied by author

Information not supplied by author

Information not supplied by author

Information not supplied by author

Dr Jürgen Barth

Senior Researcher

Department of Social and Preventive Medicine

University Berne, Institute of Social and Preventive Medicine

Niesenweg 6

Berne

3012

SWITZERLAND

E-mail: jbarth@ispm.unibe.ch

Tel: + 4131631

Fax: +41316313430

10.1002/14651858.CD006886

CD006886

Cochrane Heart Group

HM-VASC

GRAPHS AND OTHER TABLES

Figure 0I. Funnel plot

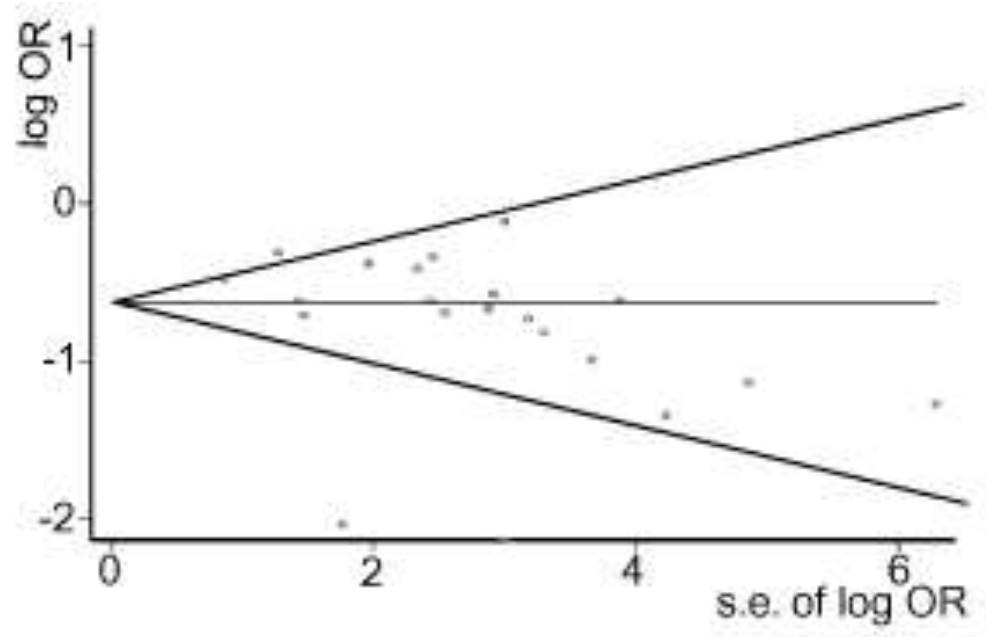

Psychosocial interventions for smoking cessation in patients with coronary heart disease (Review) 
Analysis 0I.0I. Comparison $0 \mathrm{I}$ Efficacy of psychosocial interventions on abstinence (6 to 12 months; all trials), Outcome 01 Abstinence 6 to 12 months (ITT preferred and OM)

Review: Psychosocial interventions for smoking cessation in patients with coronary heart disease Comparison: 01 Efficacy of psychosocial interventions on abstinence (6 to 12 months; all trials) Outcome: 0 I Abstinence 6 to 12 months (ITT preferred and OM)

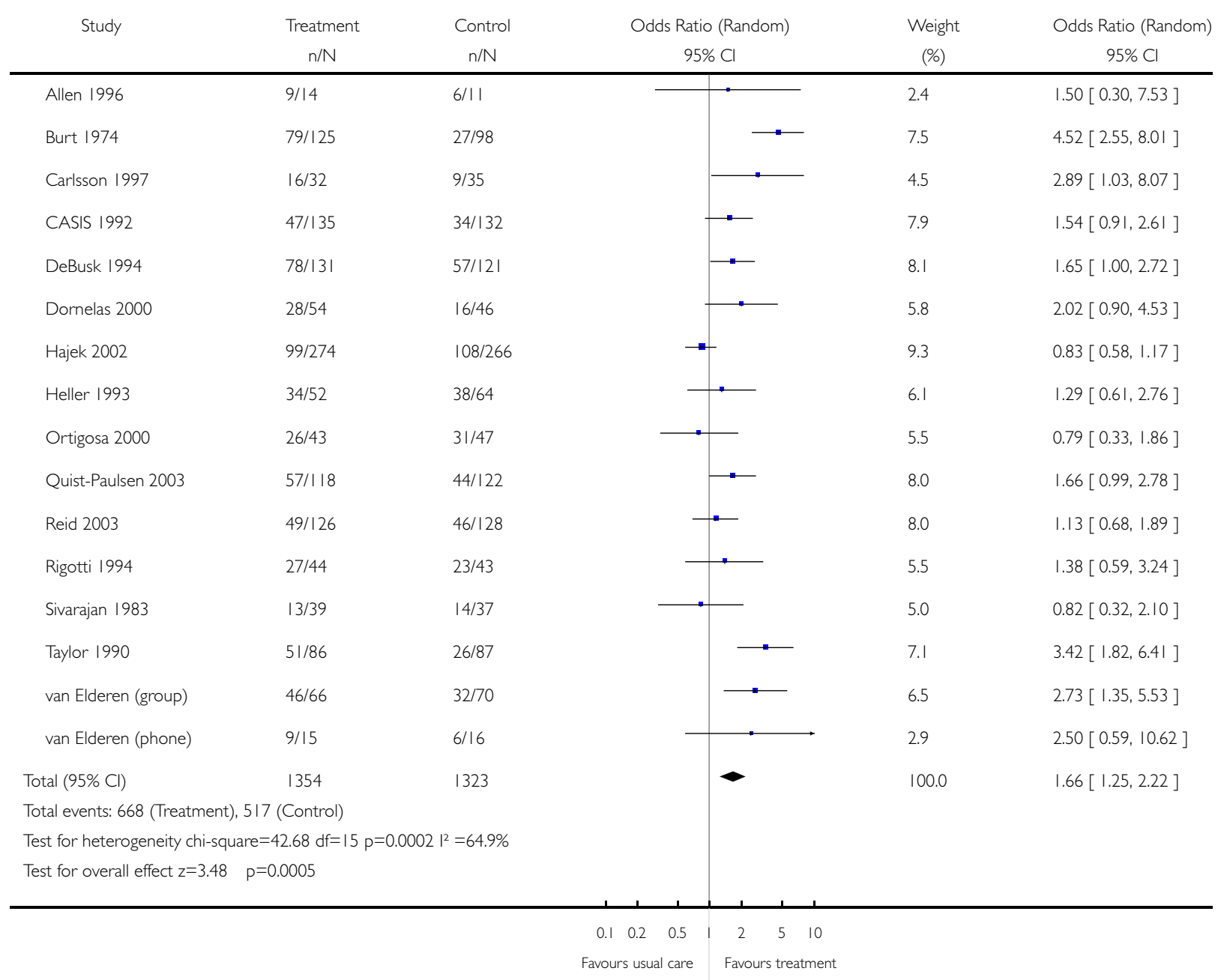


Analysis 01.02. Comparison $0 \mathrm{I}$ Efficacy of psychosocial interventions on abstinence (6 to 12 months; all trials), Outcome 02 Abstinence 6 to 12 months (ITT preferred and OM)

Review: Psychosocial interventions for smoking cessation in patients with coronary heart disease

Comparison: 01 Efficacy of psychosocial interventions on abstinence (6 to 12 months; all trials)

Outcome: 02 Abstinence 6 to 12 months (ITT preferred and OM)

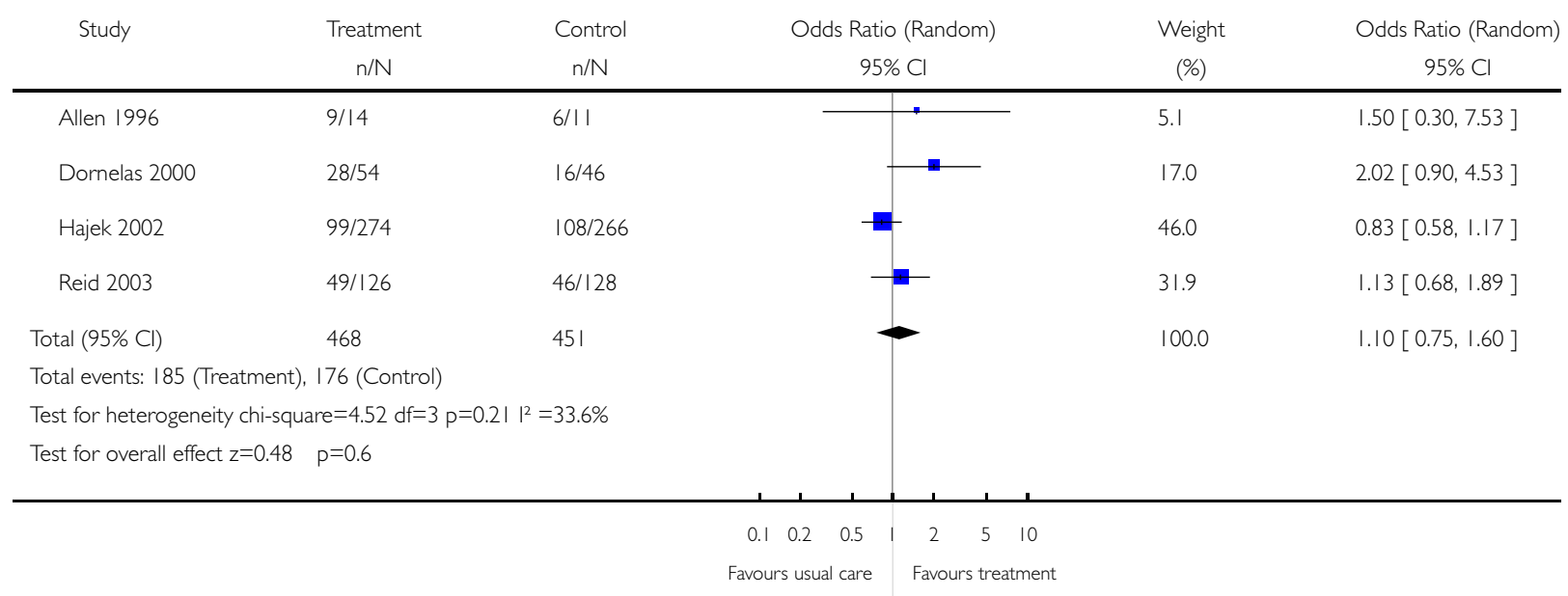

Psychosocial interventions for smoking cessation in patients with coronary heart disease (Review) 
Analysis 01.03. Comparison $0 \mathrm{I}$ Efficacy of psychosocial interventions on abstinence (6 to 12 months; all trials), Outcome 03 Abstinence 6 to 12 months (ITT only)

Review: Psychosocial interventions for smoking cessation in patients with coronary heart disease

Comparison: 01 Efficacy of psychosocial interventions on abstinence (6 to 12 months; all trials)

Outcome: 03 Abstinence 6 to 12 months (ITT only)

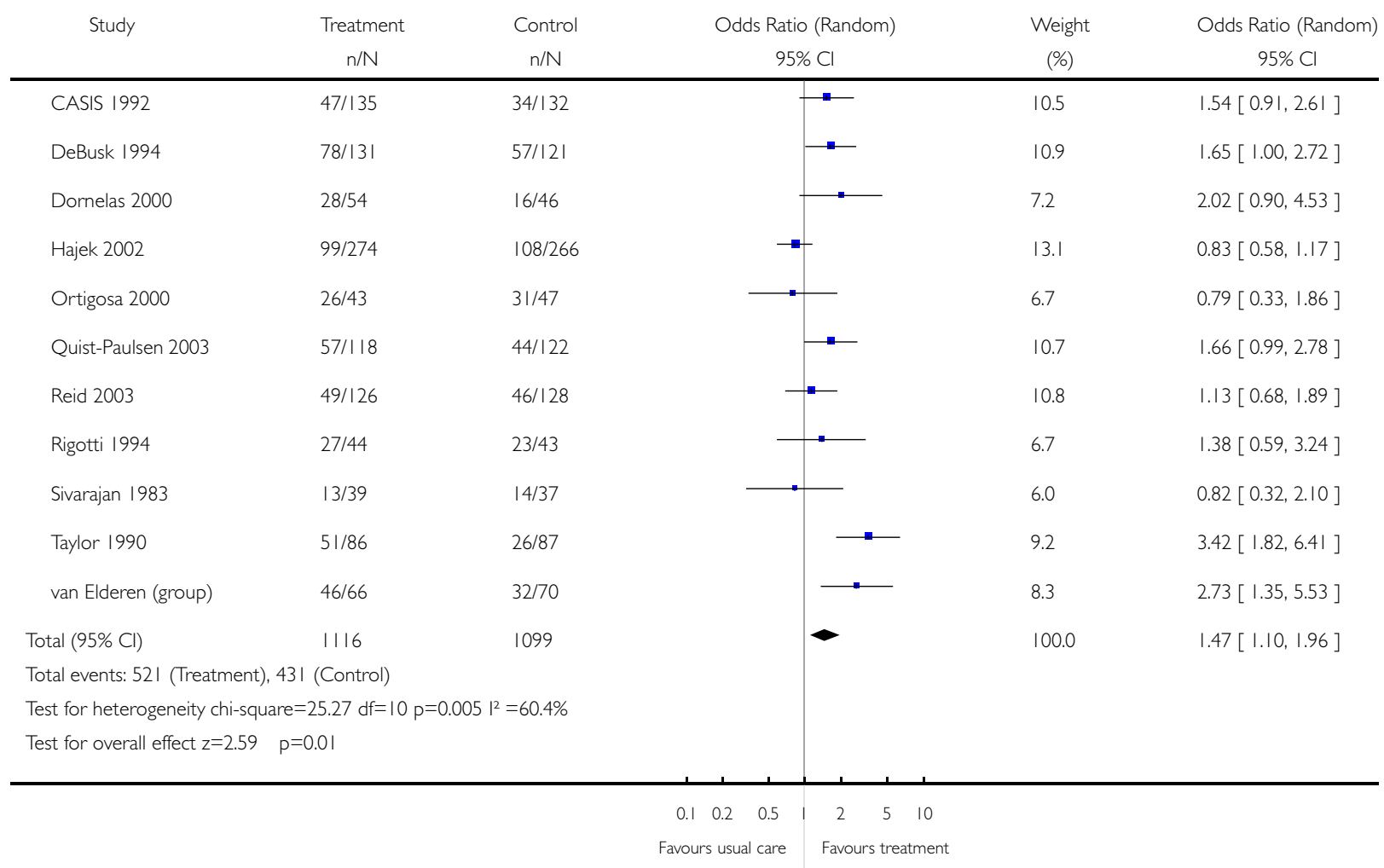

Psychosocial interventions for smoking cessation in patients with coronary heart disease (Review) 


\section{Analysis 02.0 I. Comparison 02 Sensitivity analysis validation (abstinence 6 to I 2 months), Outcome 0 I}

Abstinence at 6 to 12 months

Review: Psychosocial interventions for smoking cessation in patients with coronary heart disease Comparison: 02 Sensitivity analysis validation (abstinence 6 to 12 months)

Outcome: 01 Abstinence at 6 to 12 months

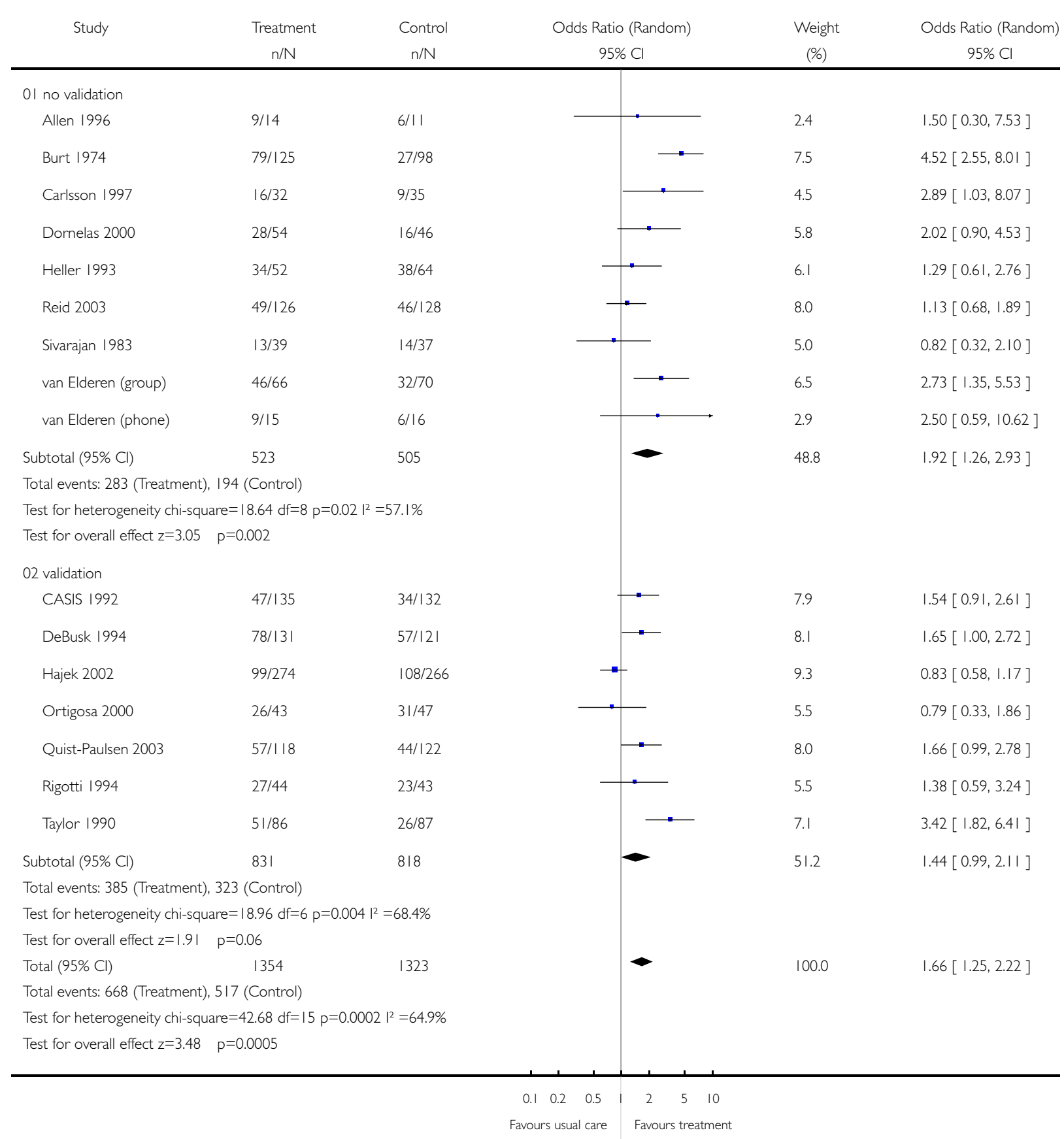

Psychosocial interventions for smoking cessation in patients with coronary heart disease (Review) 


\section{Analysis 03.0 I. Comparison 03 Grouped by type of intervention (6 to I 2 months), Outcome 0 I Abstinence 6}

to 12 months BEHAVIORAL THERAPY

Review: Psychosocial interventions for smoking cessation in patients with coronary heart disease Comparison: 03 Grouped by type of intervention (6 to 12 months)

Outcome: 01 Abstinence 6 to 12 months BEHAVIORAL THERAPY

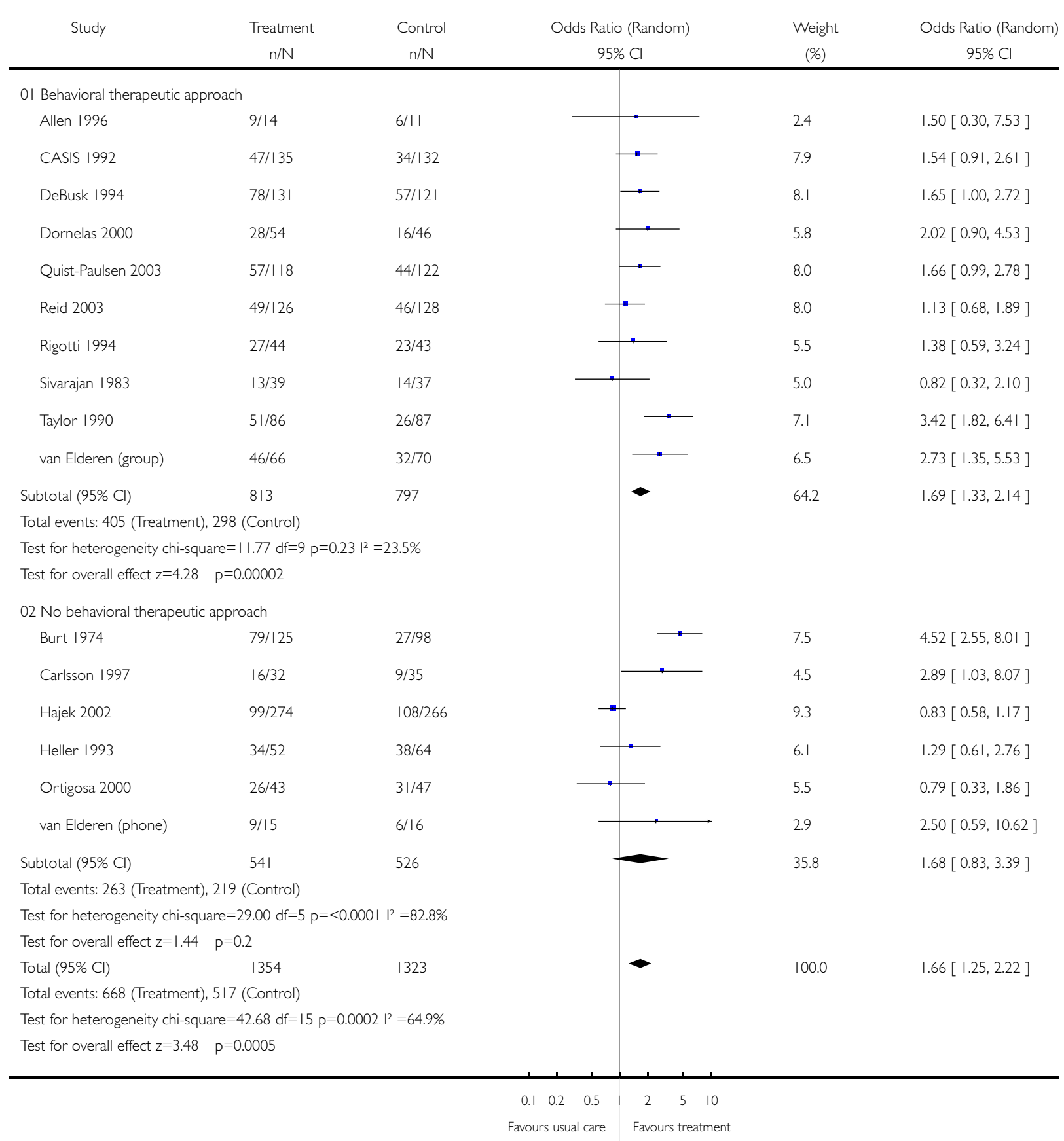

Psychosocial interventions for smoking cessation in patients with coronary heart disease (Review) 


\section{Analysis 03.02. Comparison 03 Grouped by type of intervention (6 to 12 months), Outcome 02 Abstinence 6}

to 12 months TELEPHONE SUPPORT

Review: Psychosocial interventions for smoking cessation in patients with coronary heart disease Comparison: 03 Grouped by type of intervention (6 to 12 months)

Outcome: 02 Abstinence 6 to 12 months TELEPHONE SUPPORT

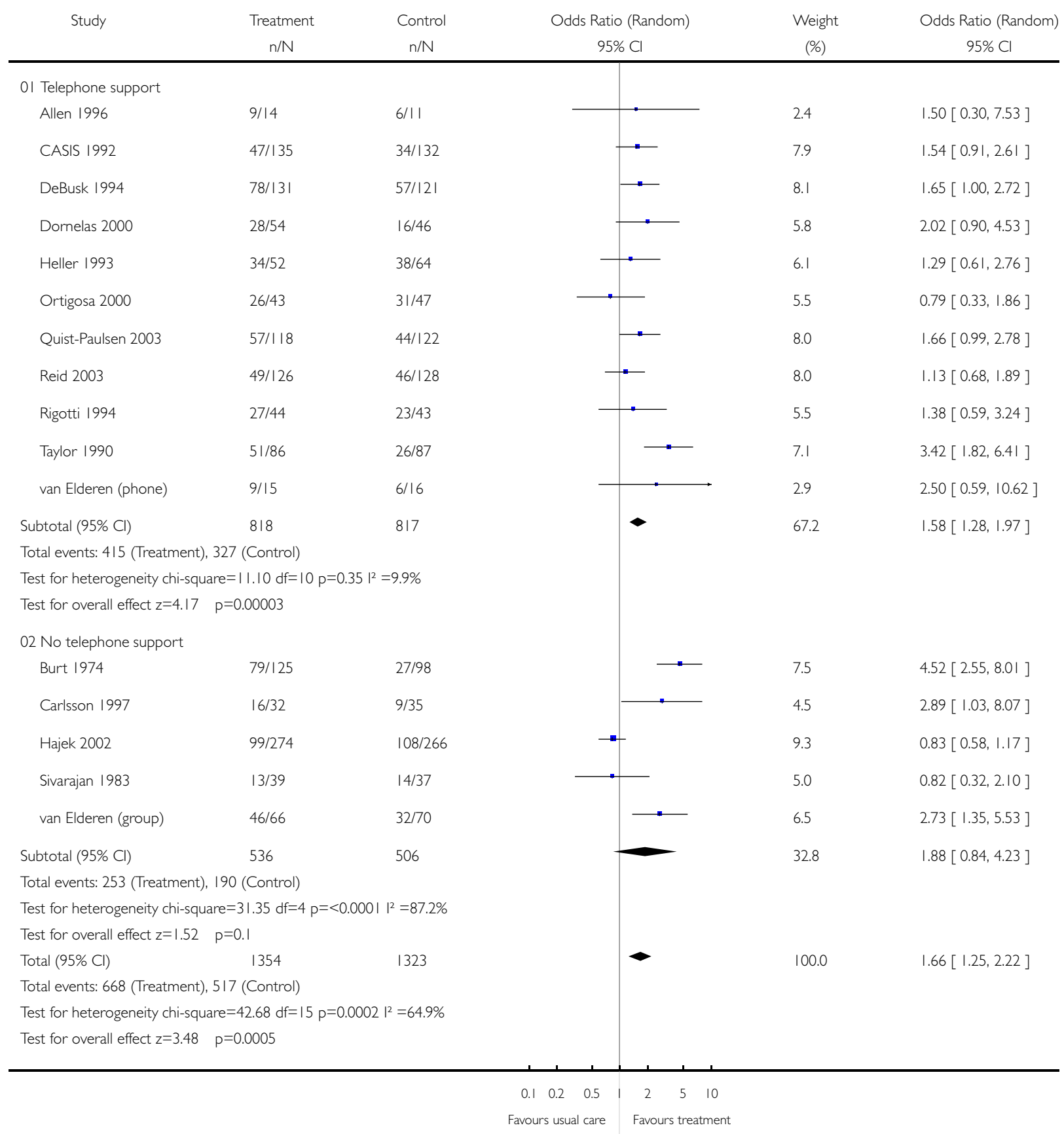

Psychosocial interventions for smoking cessation in patients with coronary heart disease (Review) 


\section{Analysis 03.03. Comparison 03 Grouped by type of intervention (6 to 12 months), Outcome 03 Abstinence 6}

to 12 months SELF HELP MATERIALS

Review: Psychosocial interventions for smoking cessation in patients with coronary heart disease Comparison: 03 Grouped by type of intervention (6 to 12 months)

Outcome: 03 Abstinence 6 to 12 months SELF HELP MATERIALS

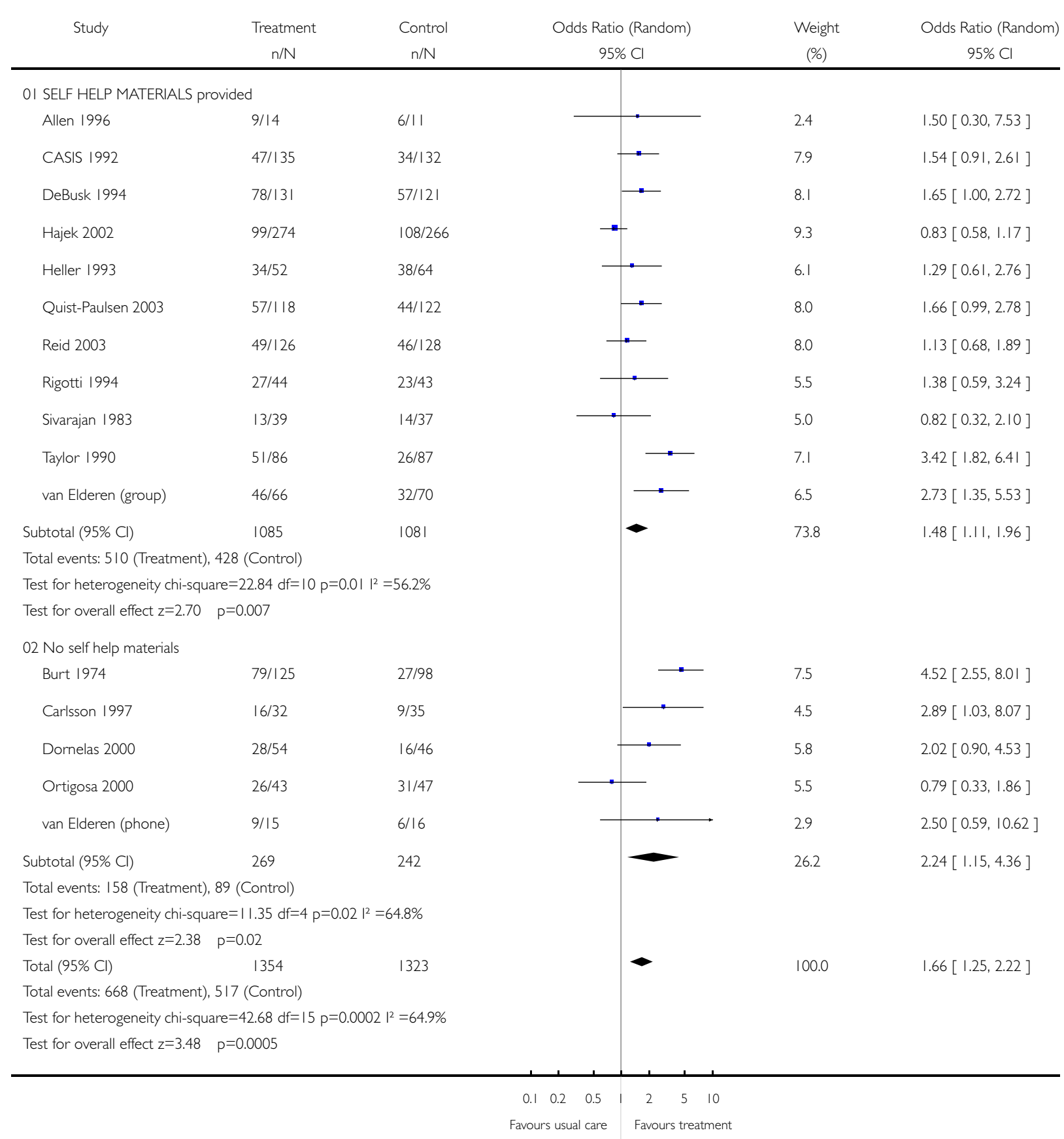

Psychosocial interventions for smoking cessation in patients with coronary heart disease (Review) 
Analysis 03.04. Comparison 03 Grouped by type of intervention (6 to 12 months), Outcome 04 Abstinence 6 to 12 months Specific vs. Multi-Risk-Factor Intervention

Review: Psychosocial interventions for smoking cessation in patients with coronary heart disease

Comparison: 03 Grouped by type of intervention (6 to 12 months)

Outcome: 04 Abstinence 6 to 12 months Specific vs. Multi-Risk-Factor Intervention

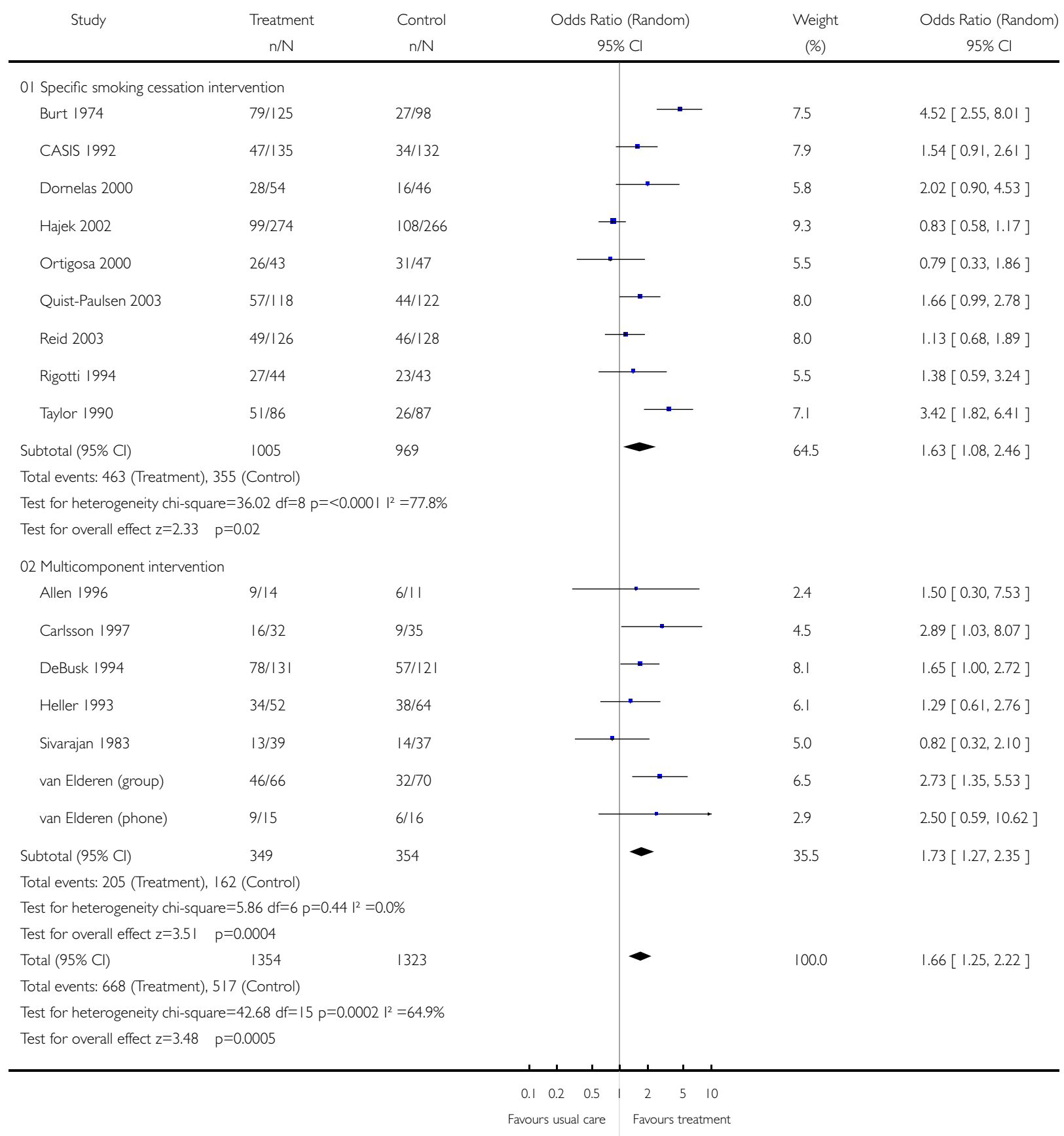

Psychosocial interventions for smoking cessation in patients with coronary heart disease (Review) 
Analysis 04.01. Comparison 04 Sensitivity analysis brief $/$ intense intervention (6 to 12 months), Outcome 01 Abstinence 6 to 12 months all studies

Review: Psychosocial interventions for smoking cessation in patients with coronary heart disease

Comparison: 04 Sensitivity analysis brief / intense intervention (6 to 12 months)

Outcome: 01 Abstinence 6 to 12 months all studies

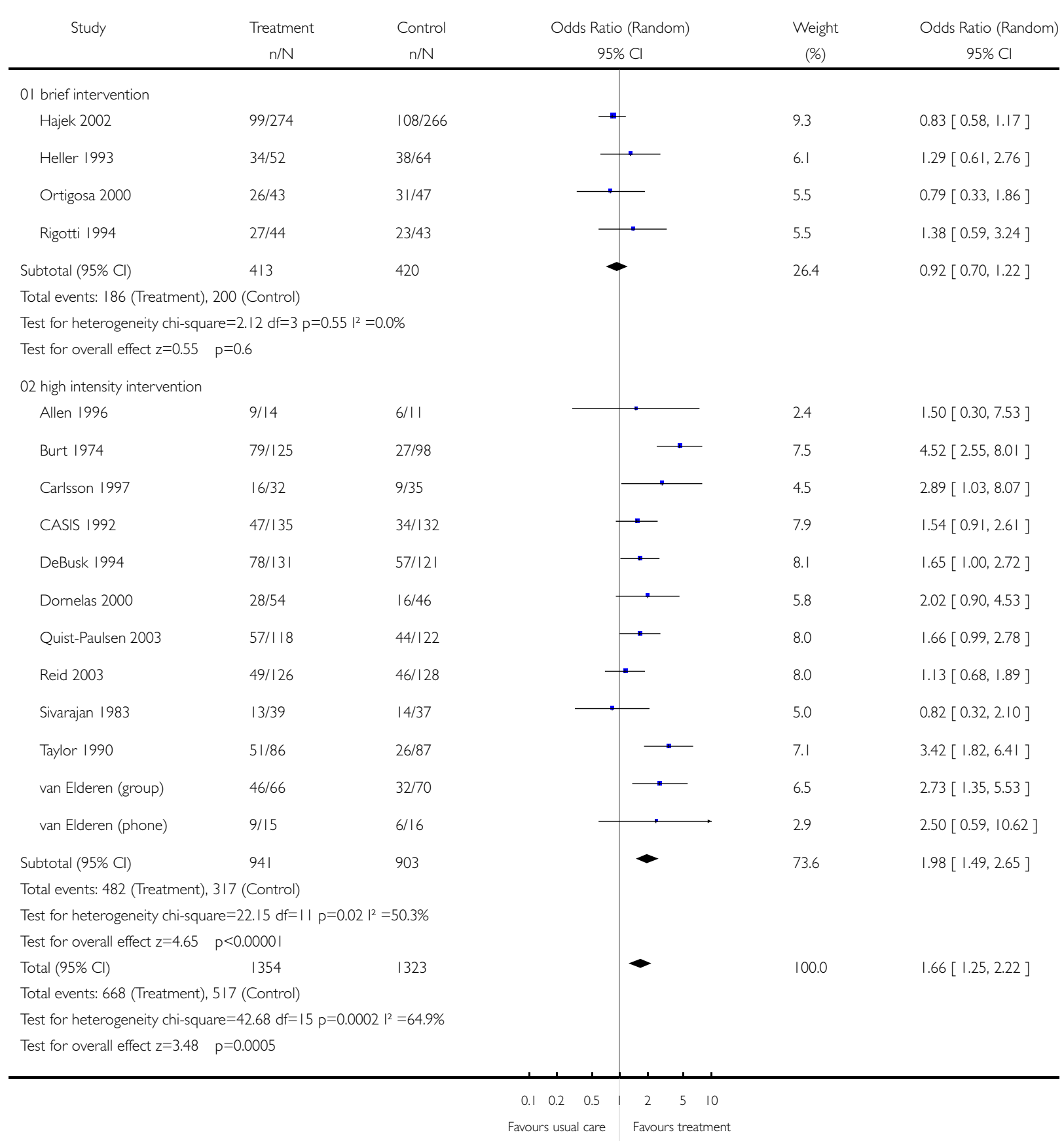

Psychosocial interventions for smoking cessation in patients with coronary heart disease (Review) 
Analysis 05.01. Comparison 05 Efficacy of psychosocial interventions on long term abstinence (five years), Outcome 0 I Abstinence five years (OM only)

Review: Psychosocial interventions for smoking cessation in patients with coronary heart disease

Comparison: 05 Efficacy of psychosocial interventions on long term abstinence (five years)

Outcome: 0 I Abstinence five years (OM only)

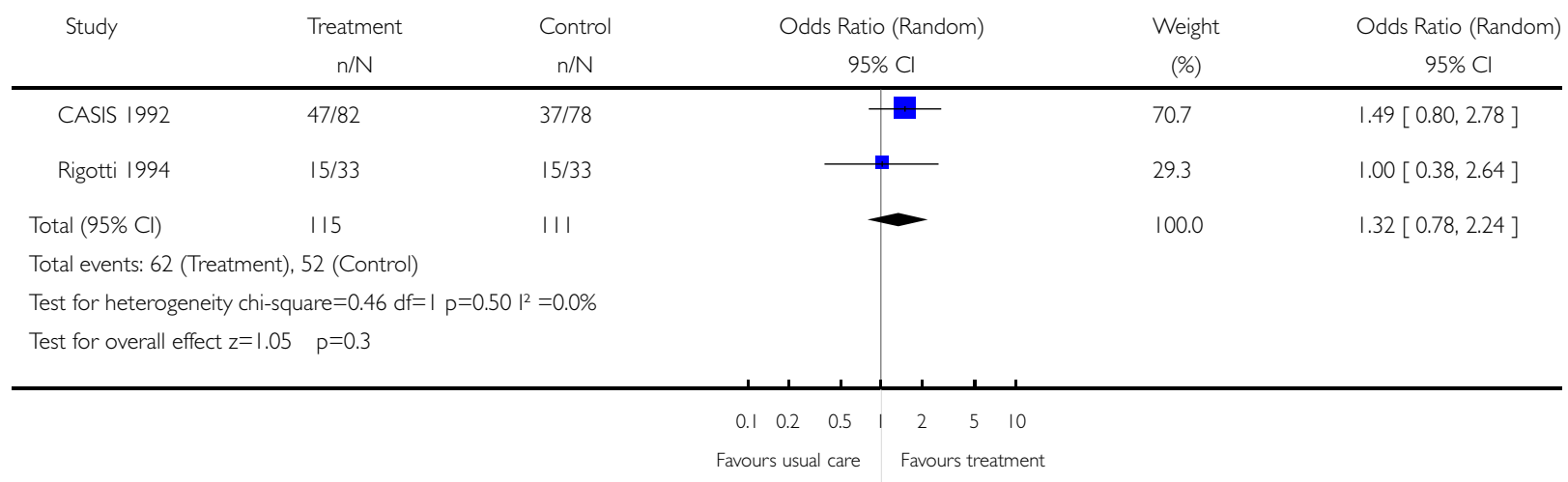

Psychosocial interventions for smoking cessation in patients with coronary heart disease (Review) 
Analysis 05.02. Comparison 05 Efficacy of psychosocial interventions on long term abstinence (five years), Outcome 02 Abstinence five years (ITT only)

Review: Psychosocial interventions for smoking cessation in patients with coronary heart disease

Comparison: 05 Efficacy of psychosocial interventions on long term abstinence (five years)

Outcome: 02 Abstinence five years (ITT only)

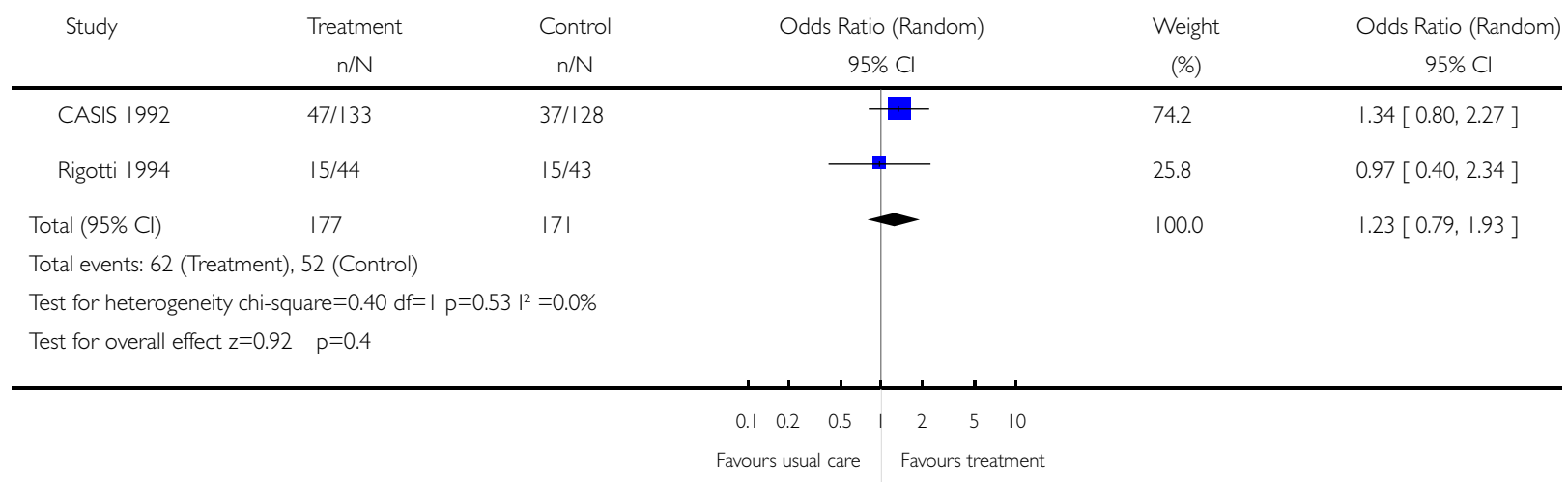

Psychosocial interventions for smoking cessation in patients with coronary heart disease (Review) 